\title{
Review of Smart-Materials Actuation Solutions for Aeroelastic and Vibration Control
}

\author{
VICTOR GIURGIUTIU* \\ Department of Mechanical Engineering, University of South Carolina, Columbia, SC 29208
}

\begin{abstract}
The paper reviews recent achievements in the application of smart-materials actuation to counteract aeroelastic and vibration effects in helicopters and fixed wing aircraft. A brief review of the induced-strain actuation principles and capabilities is done first. Attention is then focused on the smart rotor blade applications. Induced twist, active blade tip, and active blade flap are presented, with emphasis on experimental results. The fixed wing aircraft applications are considered next. Experiments of active flutter control, buffet suppression, gust load alleviation, and sonic fatigue reduction are discussed. Conclusions and directions for further work are presented at the end of the paper.
\end{abstract}

\section{INTRODUCTION}

A EROELASTIC and vibration control technology allows flight vehicles to operate beyond the traditional flutter boundaries, improves ride qualities, and minimizes vibration fatigue damage. Conventional active flutter and vibration control technology relies on the use of aerodynamic control surfaces operated by servo-hydraulic actuators as shown in Figure 1. In this conventional approach, the flutter and vibration suppression algorithms are implemented with servo-valve/hydraulic actuators. Though widely used, conventional technologies for active control of flutter and vibrations have several limitations, such as: (1) multiple energy conversions (mechanical, hydraulic, electrical); (2) large number of parts, i.e., potential failure sites and large weight penalty; (3) high vulnerability of the hydraulic pipes network; (4) frequency bandwidth limitation. Active-materials technology offers direct conversion of electrical energy to high-frequency linear motion. High-performance induced-strain actuators (piezo-electric, electro-strictive, or magneto-strictive) are capable of large forces and up to $0.1 \%$ free strain [Figure 2(a)]. This creates the opportunity for direct electrical-to-mechanical energy conversion. Electrical energy is easier to transmit throughout the aircraft, and electric lines are much less vulnerable than hydraulic pipes. The implementation of active-materials induced-strain actuation eliminates the need for hydraulic power systems, and relies directly on electrical-to-mechanical conversion [Figure 2(b)]. In spite of large force and energy capabilities, active-materials induced-strain actuators (ISA) have very small strokes, limited by the inherent $0.1 \%$ cap on the free induced-strain response (Giurgiutiu et al., 1997b). For example, a $100-\mathrm{mm}$ long actuator is capable of a mere $0.1-\mathrm{mm}$ peak-to-peak stroke. Practical implementation of induced

*E-mail: victorg@sc.edu strain actuators into aircraft control system necessarily must include displacement amplification mechanisms (Giurgiutiu et al., 1997a).

\section{HELICOPTER APPLICATIONS}

Helicopter applications of induced-strain actuation have received extensive attention (Giurgiutiu et al., 1994; Narkiewicz and Done, 1994). An extensive review was presented by Chopra (1997). Conventional actuation solutions (hydraulics and electric motors) are less attractive for on-blade actuation. Induced-strain appears as a viable alternative. Two directions have been investigated: (1) distributed induced-strain actuation resulting in a continuous twisting of the blade; and (2) discrete actuation of a servo-aerodynamic control surface (flap, tab, blade-tip, etc.) to generate localized aerodynamic forces.

\section{Induced Blade Twist}

By distributing active material elements along the flight structure, a smooth continuous deformation is obtained. Since the active materials can be embedded in the structure, this solution has clear aerodynamic advantages over the discrete actuation concepts. A number of theoretical studies have been performed to estimate the degree of twist required to effect flutter and vibration reduction benefits (Nitzsche and Breitbach, 1992; Nitzsche, 1993; Walz and Chopra, 1994). These were followed by extensive experimental work, as shown next.

\section{INDUCED TWIST THROUGH PZT WAFERS \\ EMBEDDED IN COMPOSITE BLADE STRUCTURE}

Chen and Chopra (1997) describe the construction of a 1/8-Froude scale composite blade with diagonally oriented PZT wafers embedded in the fiberglass skin (Figure 3). Elec- 


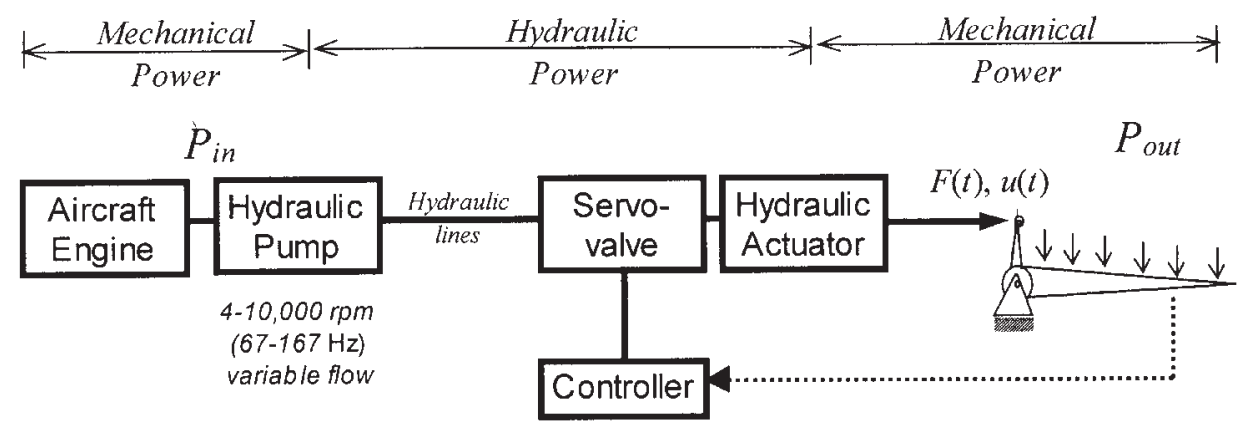

(a)

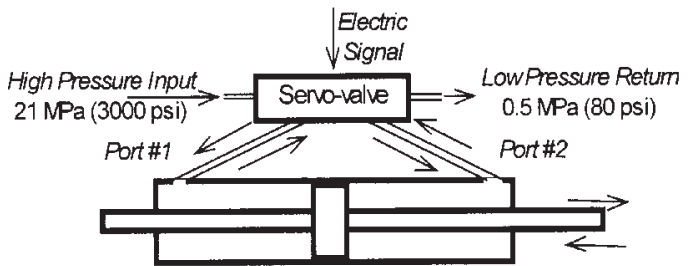

(b)

Figure 1. Present-day configuration of aircraft hydraulic system: (a) system layout and (b) details of the hydraulic actuator and servo-valve operation.

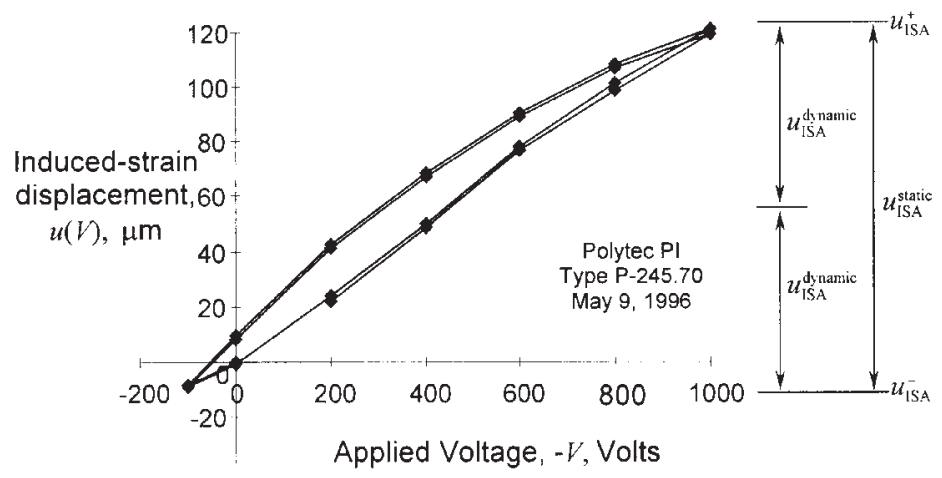

(a)
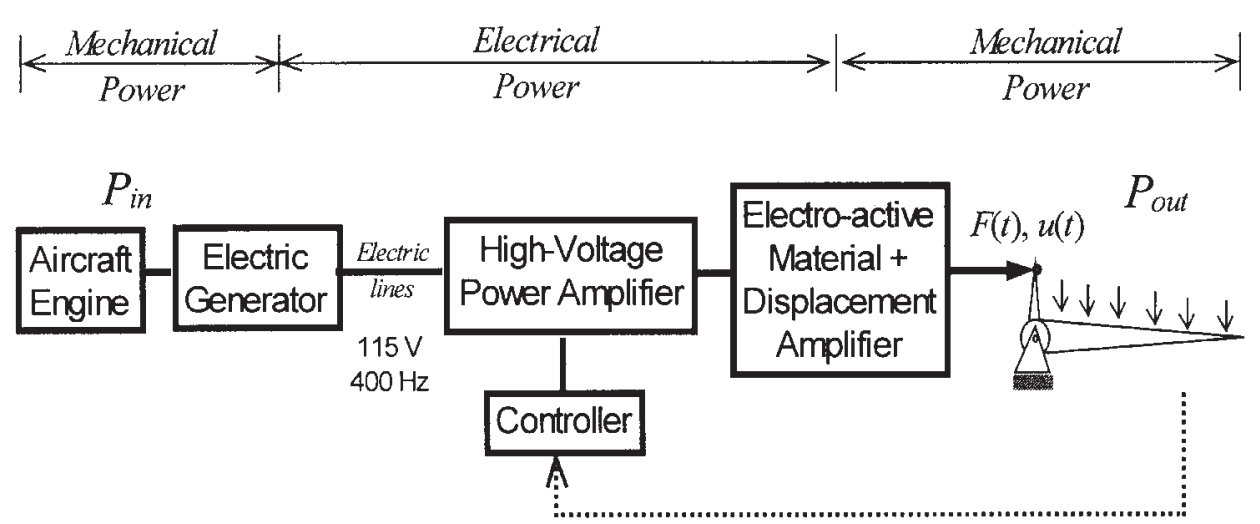

(b)

Figure 2. Active materials offer direct conversion of electrical energy in high frequency linear motion. However, their implementation into an aircraft hydraulic system cannot be achieved without displacement amplification: (a) typical displacement of a large piezoelectric stack and (b) schematic of a smart-materials flight control system. 


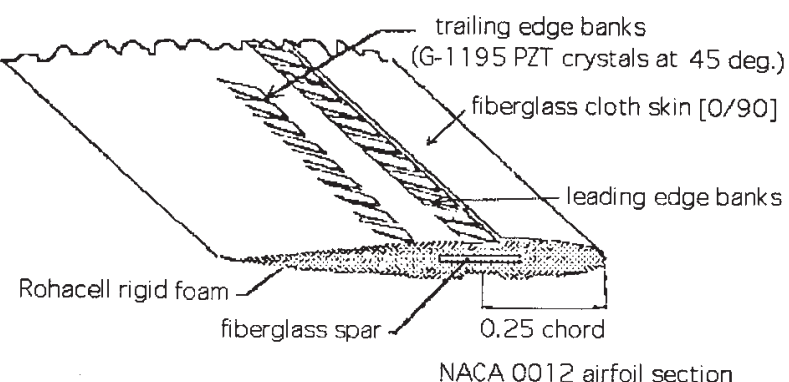

(a)

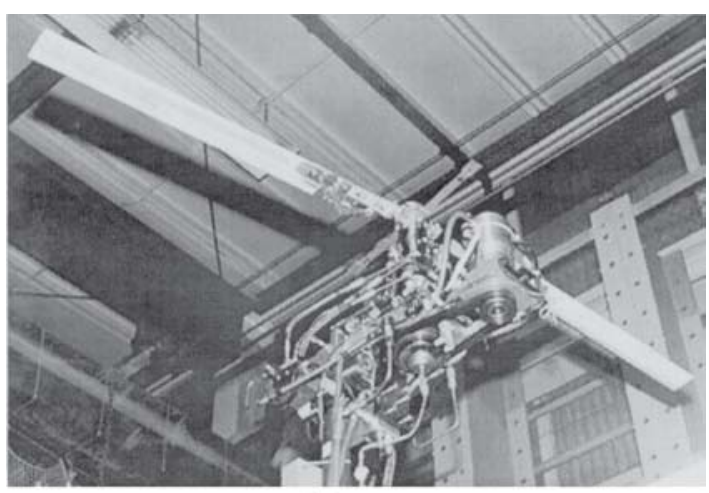

(b)

Figure 3. Induced twist through diagonally embedded PZT crystal banks: (a) schematic of the arrangement (Chen and Chopra, 1997) and (b) wind tunnel testing (Chopra, 2000).

trical activation of the PZT wafers induces twist of the blade. The blade was tested in Glenn L. Martin Wind Tunnel at the University of Maryland. Dynamic tests were performed in non-rotating and rotating conditions. Significant twist response was measured when excitation was close to resonance frequencies $(50 \mathrm{~Hz}$ and $95 \mathrm{~Hz}$ ). Maximum tip twist values at resonance frequencies were $0.35^{\circ}$ and $1.1^{\circ}$ respectively. At non-resonance frequencies, the response was less than $0.8 \mathrm{deg}$ at 4/rev excitation (Chen and Chopra, 1997).

\section{TORQUE PLATE PIEZOELECTRIC ACTUATOR FOR SOLID STATE ADAPTIVE ROTORS}

Barrett (1993) built an electrically active torque plate consisting of a metallic substrate and diagonally attached PZT wafers. Twisting of the torque plate is created by activation of the PZT elements with polarities in opposing phase on the top and bottom surfaces. A Solid State Adaptive Rotor (SSAR), consisting of the ISA torque plate attached to the root of a Froude scale composite blade, was constructed [Figure 4(a)]. Activation of the torque plates produced pitch deflections of the blade. Bench tests showed a resonance peak at $\sim 42 \mathrm{~Hz}$, followed by the typical $3 \mathrm{~dB}$ drop (Barrett and Stutts, 1997). The twist amplitude measured at resonance was in excess of $10^{\circ}$ [Figure 4(b)]. The torque plate concept was applied to in-flight demonstration of a ISA control of model helicopter. A Kyosho Hyperfly helicopter model, featuring a Hiller servo-paddle control system was used. The complicated swash-plate assembly was stripped

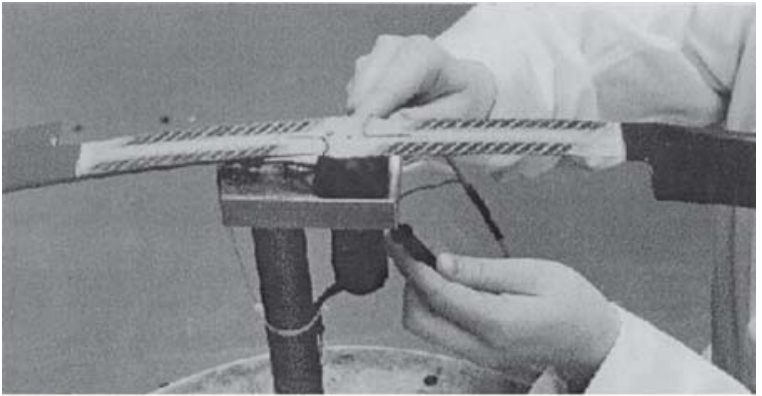

(a)

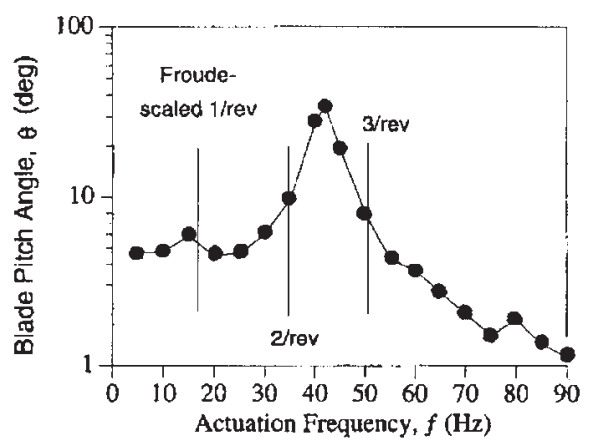

(b)

Figure 4. (a) Bench testing of a solid state induced-strain actuated model helicopter rotor and (b) dynamic pitch amplitude of a solid-state model helicopter rotor under non-rotating conditions showing a resonance peak at $\sim 42 \mathrm{~Hz}$, followed by the typical $3 \mathrm{~dB}$ drop (Barrett and Stutts, 1997).

from the model helicopter and full control authority was turned over to a pair of ISA-activated Hiller servo-paddles [Figure 5(a)]. Removal of the swash-plate assembly reduced the flight control weight by $40 \%$, the aircraft gross weight by $8 \%$, and the parasite drag by $26 \%$ through appropriate fairing (Barrett, Frye, and Schliesman, 1998). Flight testing of the model was successfully performed [Figure 5(b)].

\section{Active Fiber Composites for Rotor Blade Twist}

Active fiber composites consist of a laminated structure of fiberglass plies and PZT-fiber plies. The PZT-fiber plies have continuous, aligned, PZT fibers in an epoxy layer, and polyimide/copper electrode films (Figure 6). The electrode films are etched into an inter-digitated pattern that effects electric field along the fiber direction, thus activating the primary $d_{33}$ piezoelectric effect (Rodgers and Hagood, 1998). As shown in Figure 6, The PZT fiber can be either fabricated individually (Rodgers and Hagood, 1998), or cut from PZT plates (Wilkie et al., 2000).

Active fiber composites (AFC) were incorporated into the construction of a $1 / 6$ th Mach scale $\mathrm{CH}-47 \mathrm{D}$ blade model (60.619-in span and 5.388-in chord) for wind tunnel testing at Boeing Helicopters (Philadelphia). Three diagonally placed active-fiber composite plies were incorporated in the co-cured D-spar blade lay-up. Activation of the diagonally 


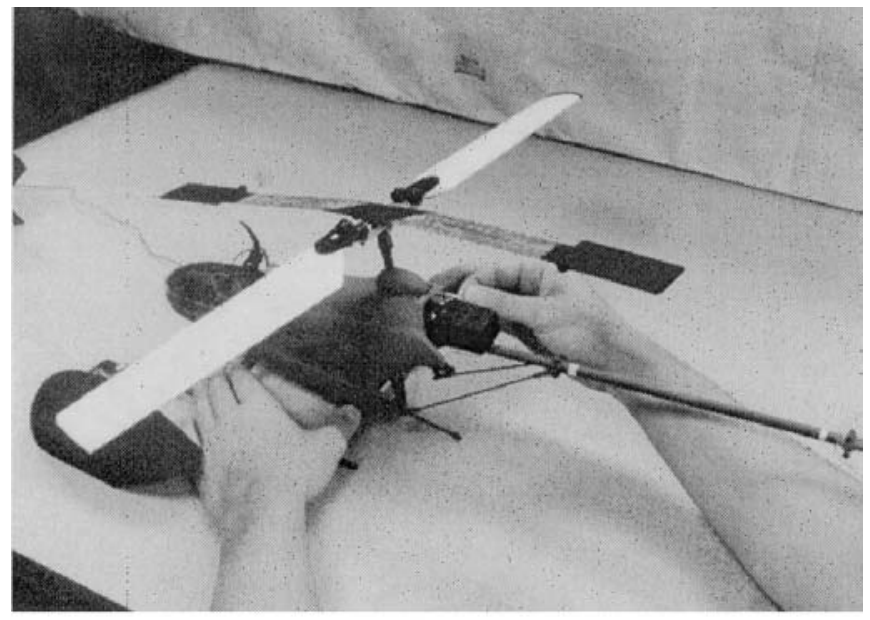

(a)

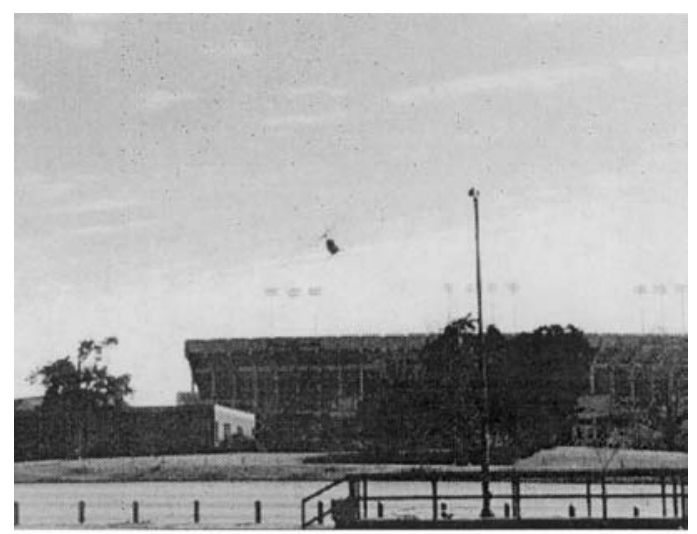

(b)

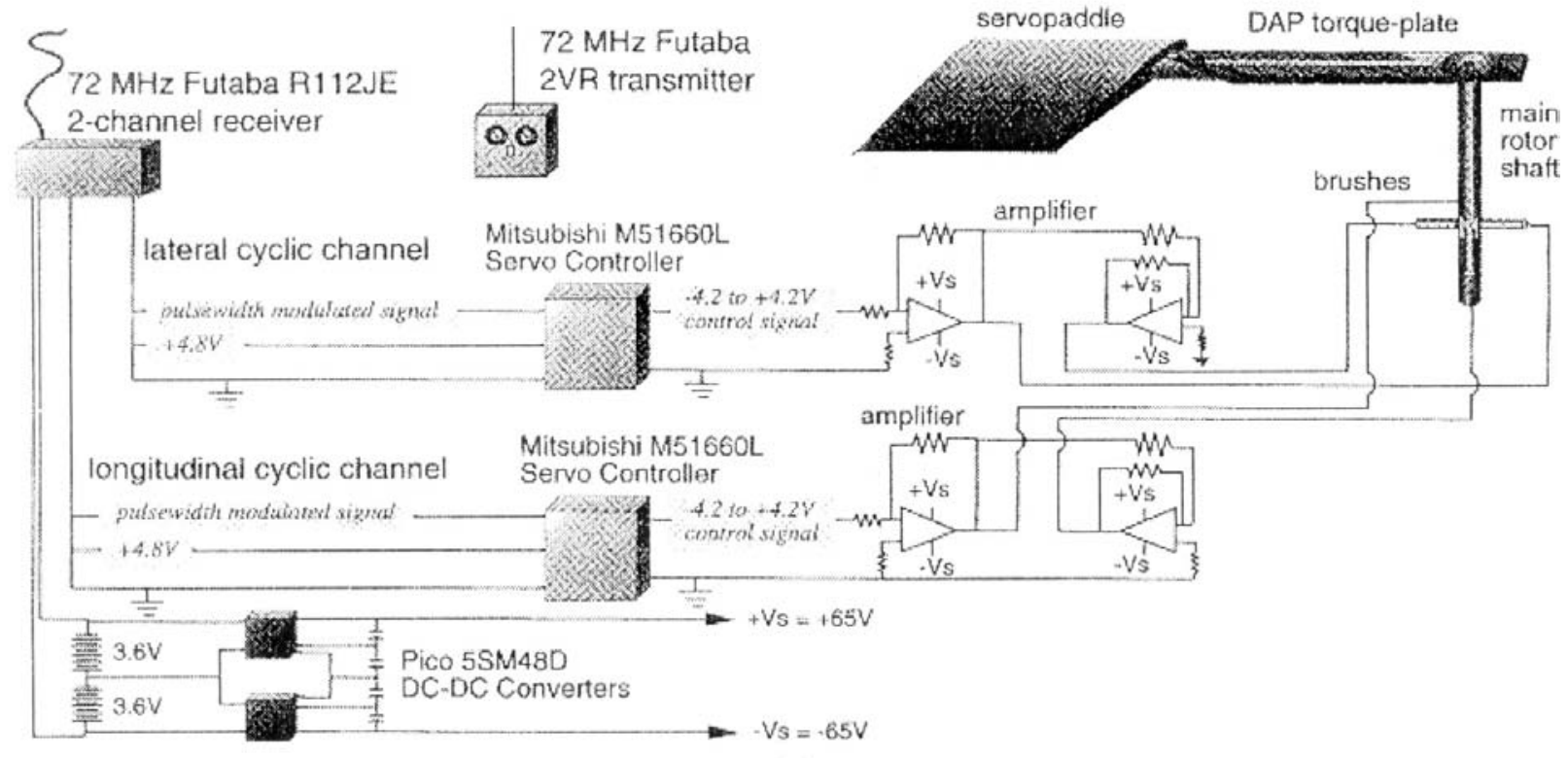

(c)

Figure 5. Model helicopter Gamara, equipped with piezoelectrically activated Hiller paddle: (a) bench tests, (b) flight demonstration and (c) schematic of the power and active control systems (Barrett, Frye, and Schliesman, 1998). 
(a)

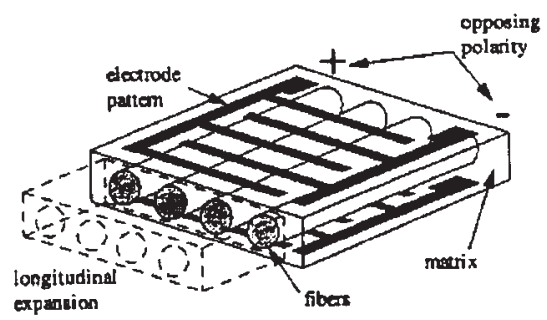

expansion

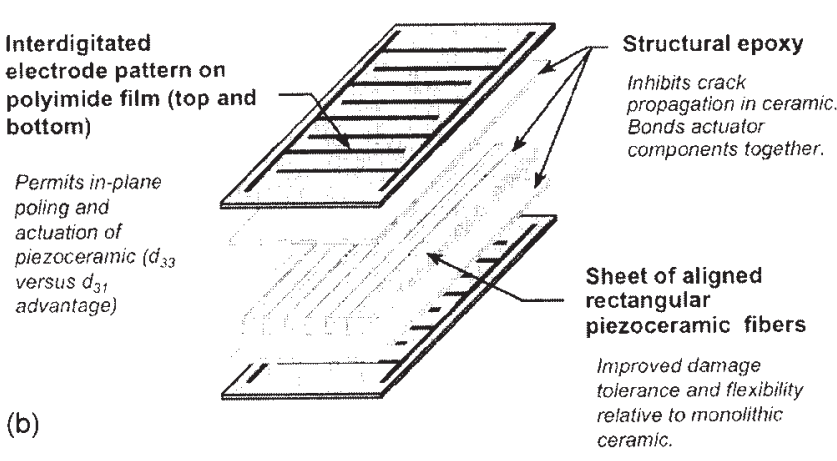

Figure 6. Active fiber composite (AFC): (a) schematic representation of PZT-fiber composite illustrating the inter-digitated electrodes and the longitudinal expansion of the fibers (Rodgers and Hagood, 1998) and (b) NASA Langley RC Macro-Fiber Composite ${ }^{T M}$ actuator components (Wilkie et al., 2000).

placed fibers induces shear in the spar skin, which generates blade twist. A design goal of $\pm 2^{\circ}$ blade twist was set. The blade specimen contained 7 groups of 6 AFC packs ( 3 in the top plies and 3 in the bottom) as shown in Figure 5(a). Of the 42 AFC packs installed in the blade, 11 were found to have poor electrical connection, and could not be activated. Thus, the blade actuation authority was somehow impaired. Bench tests performed at frequencies up to $67.5 \mathrm{~Hz}$ demonstrated a maximum twist authority of between 1 and $1.5^{\circ}$ peak-to-peak ( \pm 0.5 to $\pm 0.75^{\circ}$ amplitude). The full-length blade specimen was tested in a hover stand at 800 to 1336 $\mathrm{rpm}$. The blade demonstrated hover testing resulted in recorded torsional strain and vertical hub force. At present, the active fiber technology is undergoing environmental stress evaluation (Morris, Pizzochero, and Hagood, 1999).

In a separate effort, Wilbur et al. (1999) constructed the NASA/APL/MIT active twist rotor (ATR) and hover tested it in the Transonic Dynamic Tunnel (TDT) at NASA Langley Research Center. The active twist rotor consisted of an ATR blade and three passive blades of similar mass and geometry. The ATR blade [Figure 7(b)] was constructed using active fiber composite plies [Figure 8(a)]. During tests [Figure 8(b)], the wind tunnel was filled with heavy gas $\left(2.4 \mathrm{~kg} / \mathrm{m}^{3}\right)$ to achieve better Mach-scale similarity. Based on measured bending moment response, it was estimated that 1 to $1.5^{\circ}$ maximum twist was generated for the $4 \pm 1 / \mathrm{rev}(33-55 \mathrm{~Hz})$ frequency range at $1000 \mathrm{~V}$ electric excitation. Simulated forward flight experiments of an improved rotor will follow. Aeroelastic modeling of the ATR performance was per- formed by Wilkie et al. (1999). Extensive modeling of the ATR blade actuation mechanism was performed by Cesnik et al (1999), and by Cesnik and Shin (1999). A two-cell model of the blade cross section was developed, and relative stiffness parameter studies were performed to identify optimal configuration.

\section{Active Blade Tip with Bending-Torsion ISA Actuator}

Bernhard and Chopra (1998) studied the smart active blade tip (SABT) concept for rotor blade vibrations and aeroelastic control (Figure 9). An all-movable blade tip is driven in rotational motion by an induced-strain rotary actuator placed inside the blade. It consists of span-wise segments of structural layers [+45/0/-45] and diagonally placed directionally attached PZT wafer actuators. The actuator operates on the coupled bending-torsion principle. The span-wise segments are differentially energized such that, the induced-strain bending curvatures cancel out, while the induced-strain twist curvatures add up to create a net tip rotation. A model-scale bending-torsion actuator beam of 546 $\mathrm{mm}$ length, $25.4 \mathrm{~mm}$ width and $2 \mathrm{~mm}$ thickness was constructed and used for active blade tip and active blade twist experiments. Active blade tip experiments were performed with the bending-torsion ISA actuator incorporated into a $1 / 8$ Froude scale blade for a 6 -ft $(1.83 \mathrm{~m})$ bearingless rotor model. A $10 \%$ span smart active blade tip (SABT) was placed at the blade outer end. The blade tip response at 930 $\mathrm{rpm}$ varied between $2^{\circ}$ and $2.5^{\circ}$ for $1,2,3,4$, and 5/rev excitation frequencies [Figure 10(b)]. Active blade twist experiments were also performed with the bending torsion ISA actuator incorporated into a 1/8 scale Froude scale blade for a 6-ft $(1.83 \mathrm{~m}$ ) bearingless rotor model (Bernhard and Chopra, 1998). Through a suitable root and tip clamping, activation of the bending-torsion actuator created twist of the blade. Hover tests at $875 \mathrm{rpm}$ produced blade twist results from $0.3^{\circ}$ at $1 / \mathrm{rev}$ through $0.5^{\circ}$ at $5 / \mathrm{rev}$ excitation-frequencies.

\section{Rotor Blade Flap Actuation}

Servo-flap concepts have been investigated as an alternate approach to achieving induced-strain rotor blade actuation. Theoretical studies (Millott and Friedmann, 1994) highlighted the aerodynamic servo-flap concept benefits for active helicopter rotor control. The studies used an extensive aeroelastic model (including geometrical non-linearities and advanced unsteady aerodynamic 2-D models) that was coupled with a vibration-reduction controller. Substantial vibration reductions were demonstrated at various helicopter airspeeds corresponding to advance ratios in the range $\mu=0$ to 0.4 . The required flap travel, hinge moment, and average power consumption were calculated.

\section{BIMORPH SERVO-FLAP ACTUATION}

Bimorph piezoelectric actuators (Figure 11) were used in early servo-flap experiments targeting the Boeing $\mathrm{CH}-47 \mathrm{D}$ 


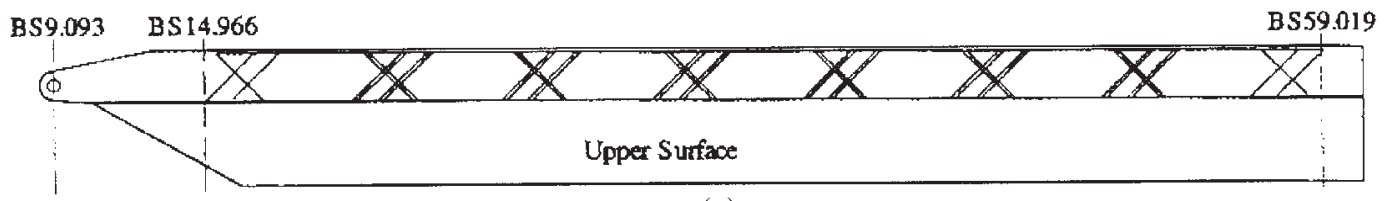

(a)

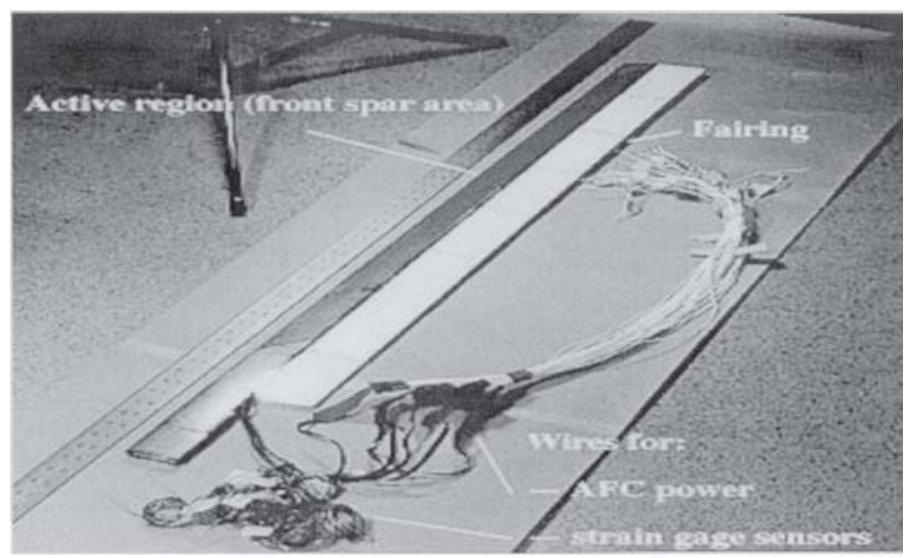

(b)

Figure 7. (a) Schematic representation of a scaled C-47D blade specimen (1-m active length) indicating the location of 7 groups of AFC packs (Rodgers and Hagood, 1998) and (b) photograph of the Active Twist Rotor (ATR) blade indicating details of the electrical connections (Wilbur et al., 1999; Cesnik et al., 1999).

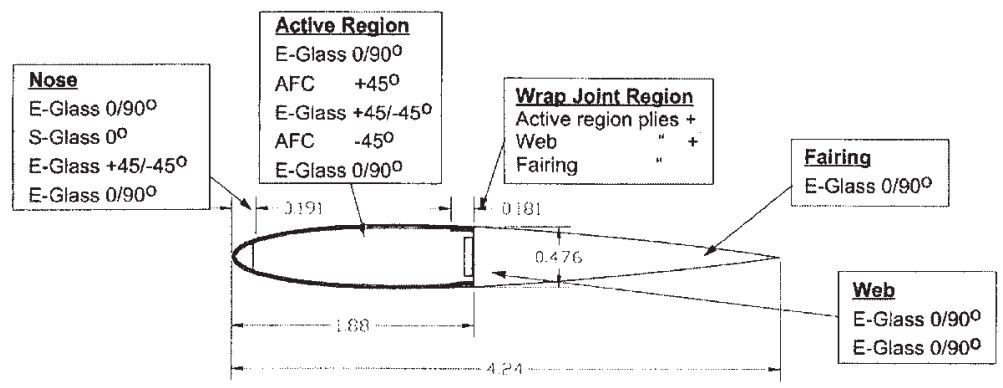

(a)

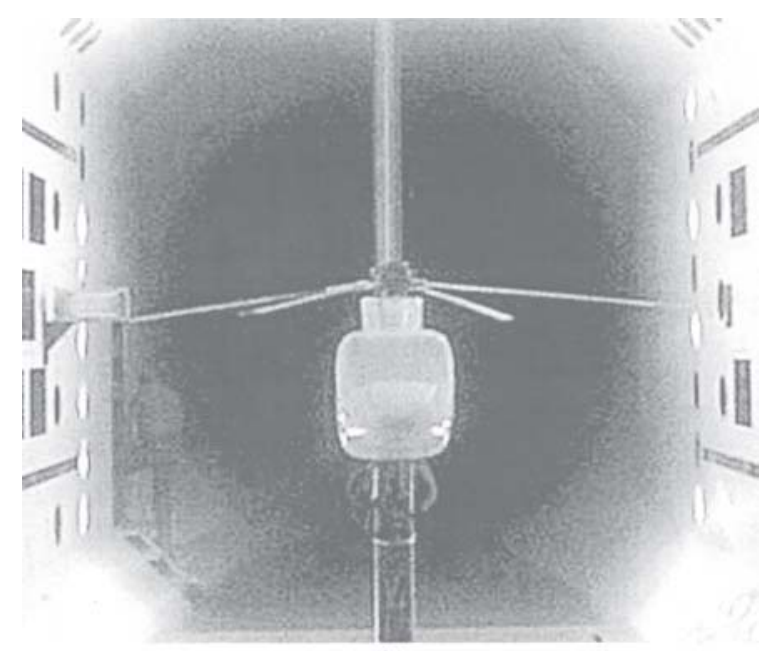

(b)

Figure 8. Active Twist Rotor (ATR): (a) construction details and (b) ATR mounted in the Transonic Dynamic Tunnel (TDT) at NASA Langley Research Center (Wilbur et al., 1999; Cesnik et al., 1999). 


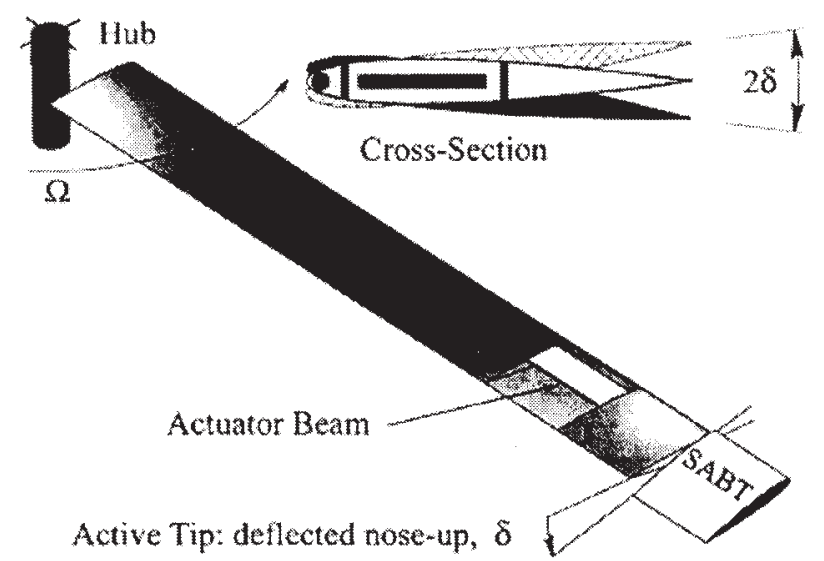

Figure 9. The smart active blade tip (SABT) concept consists of all-movable blade tip driven by span-long actuator beam placed inside the blade (Bernhard and Chopra, 1998).

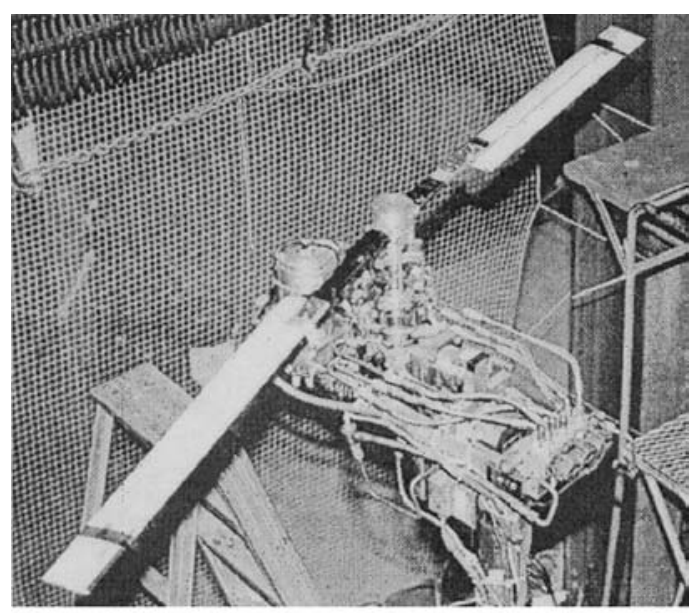

(a)

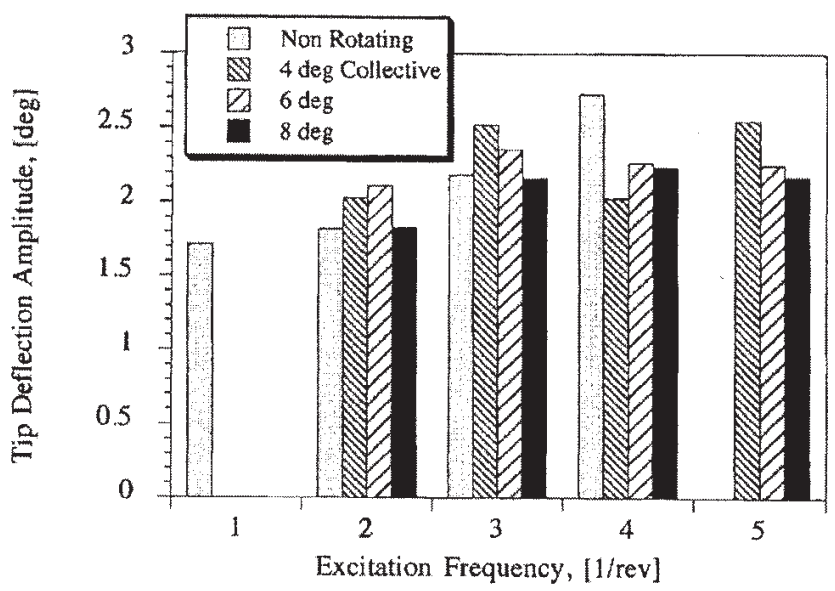

(b)

Figure 10. (a) SBAT 1/8th Froude scale model being tested in the University of Maryland hover stand and (b) tip deflections of up to $2.5^{\circ}$ were recorded at $930 \mathrm{rpm}$ (Bernhard and Chopra, 1999).

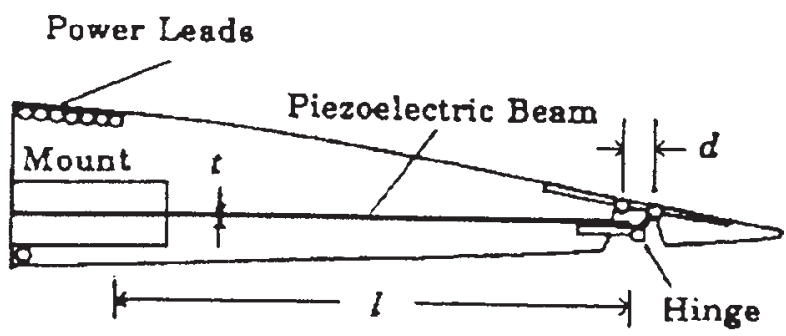

Figure 11. Schematic of early bimorph-activated trailing edge flap specimen (Spangler and Hall, 1989).

tandem helicopter (Spangler and Hall, 1989). A 1/5-scale stationary-model with a $10 \%$ chord flap was wind-tunnel tested at various air speeds between zero and $78 \mathrm{ft} / \mathrm{sec}$, and at frequencies up to $100 \mathrm{~Hz}$. Significant flap deflection, lift, and pitching moments were recorded, but the values were below the theoretical predictions. An improved design using a multilayer ISA bender actuator, solid state flexural hinges, and impedance matching principles, was subsequently conceptualized, manufactured, and tested (Hall and Prechtl, 1996), with good bench-test results $\left( \pm 11^{\circ}\right.$ flap deflection over the $0-90 \mathrm{~Hz}$ bandwidth). However, due to inherent limitations in the bimorph excitation concept (low mass efficiency and need for leading edge balance weights) this line of investigation was discontinued; attention was re-focused on ISA stacks (Prechtl and Hall, 1997).

Walz and Chopra (1994), and Koratkar and Chopra (1998, 2000) also used Bimorph ISA rotor blade flaps. Initially, Walz and Chopra (1994) used trailing edge flaps of $20 \%$ chord, $12 \%$ span $(0.85 \mathrm{R}-0.97 \mathrm{R})$ built into a 36 in radius, 3 in chord composite blade model (Figure 12). Later, Koratkar and Chopra (1998) used a 4\%-span flap actuated by a 4-layer PZT bimorph actuator. A Hall sensor was incorporated into the blade to measure flap deflection during rotating blade testing. The testing was performed at various collective pitch values up to $4^{\circ}$ collective pitch. Flap deflections of $\pm 8^{\circ}$ were measured with the Hall sensor at the Froude scaled operating speed 900 rpm (Figure 13). Further tests were performed on a Mach-scaled rotor. For $10 \mathrm{~Hz}$ excitation, flap deflection from $\pm 10^{\circ}$ (non-rotating) to $\pm 5.7^{\circ}$ (rotating at $1800 \mathrm{rpm}$ ) were obtained. The flap deflection was also shown to increase with frequency from $\pm 6^{\circ}$ at $1 / \mathrm{rev}$ to $\pm 10^{\circ}$ at $4 / \mathrm{rev}$. Fulton and Ormiston $(1997,1998)$ also used bimorph flap actuation to control a $10 \%$-chord, $12 \%$-span elevon mounted on a $1.143 \mathrm{~m}(7.5-\mathrm{ft})$ radius two-blade rotor. Elevon deflections of up to $\pm 10^{\circ}$, for non-rotating conditions, and $\pm 5^{\circ}$, at $760 \mathrm{rpm}$, were demonstrated at frequencies up to $4 / \mathrm{rev}$. Reduction in vibratory blade load in forward flight was demonstrated.

\section{PIEZOSTACKS ACTUATED SERVO-FLAPS}

Prechtl and Hall (1997) built a mechanically amplified ISA flap actuator (X-frame actuator) using a pair of EDO Corp. EC-98 PMN-PT piezo-ceramic stacks with 140 layers of 0.0221 -in thick $=3.1$-in $(\sim 80 \mathrm{~mm})$ active length. During 


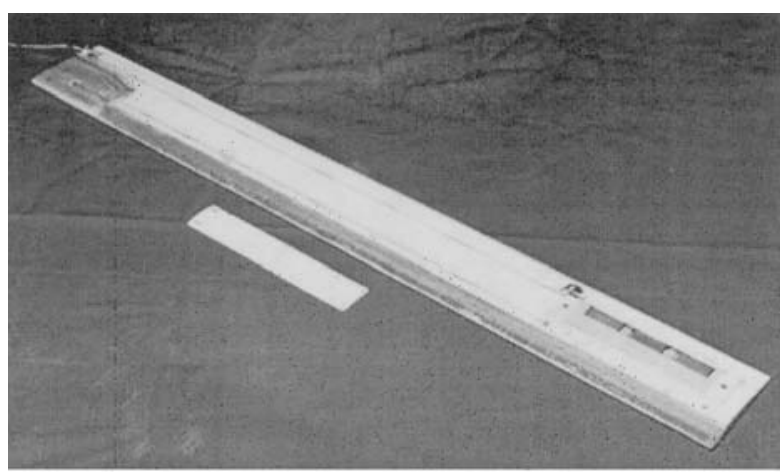

(a)

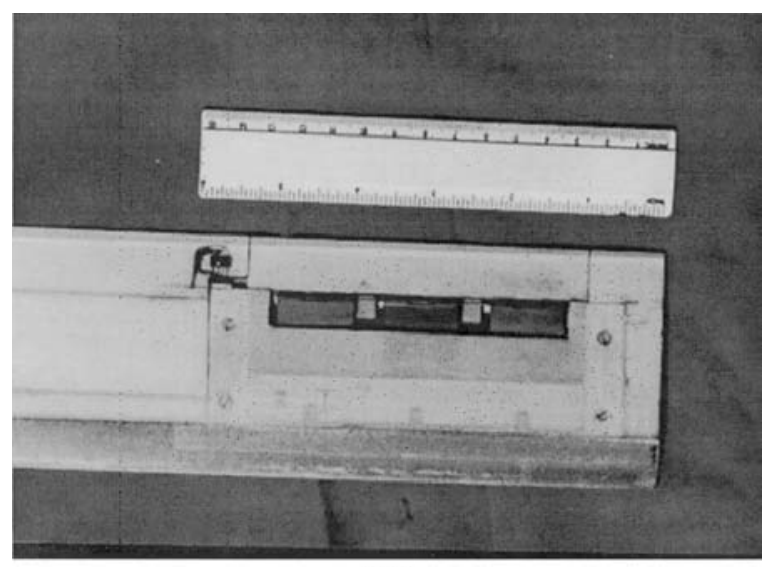

(b)

Figure 12. Scaled rotor blade with piezoelectric bimorph actuated trailing edge flap: (a) view of the complete blade and (b) detail of the flap actuation region (Chopra, 2000).

bench tests, the actuator showed $81 \mathrm{mil}(\sim 2.057 \mathrm{~mm})$ free displacement, for frequencies up to $200 \mathrm{~Hz}$, and a blocked force of 35.8-lb $(\sim 156 \mathrm{~N})$, sustained under up to $69-\mathrm{g} 135-\mathrm{Hz}$ shaking (Hall and Prechtl, 1999). In a 1/6 Mach scale CH-47D rotor blade model, the $\mathrm{X}$-frame actuator occupies the leading edge part of the airfoil (Figure 14). Mechanical linkages (control rod and reaction tube) are used to actuate the trailing edge flap horn and return the reactions into the actuator structure (Prechtl and Hall, 1998). In the scaled rotor blade model, deflection amplitudes of almost $10^{\circ}$ sustained for increasing frequencies up to $150 \mathrm{~Hz}$, were recorded (Figure 15). Lee and Chopra $(1998,2000)$ also reported using piezostacks for servo-flap actuation of scaled rotor blade. A two-stage (L-L) displacement amplification mechanism and Physik Instrumente P-804.10 piezostacks were used. The L-L actuator was installed in the spar of a blade section and mechanically connected to a trailing edge flap (Figure 16). Wind tunnel test at speed up to $120 \mathrm{ft} / \mathrm{sec}$ and angle of attack of up to $12^{\circ}$ demonstrated peak-to-peak deflection of $13^{\circ}$ for $1 / \mathrm{rev}, 19^{\circ}$ for $2 / \mathrm{rev}, 17.5^{\circ}$ for $3 / \mathrm{rev}$, and $8^{\circ}$ for $4 / \mathrm{rev}$.

Spencer, Sanner, and Chopra (1999) studied the use of adaptive neurocotrollers for reducing the rotor vibrations us-

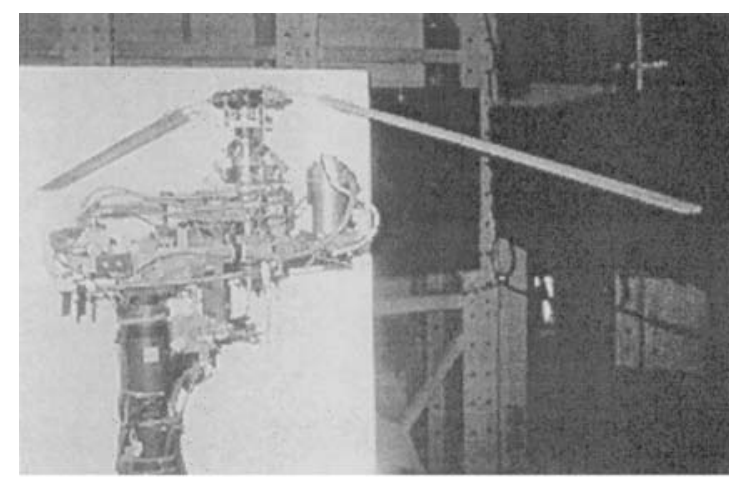

(a)

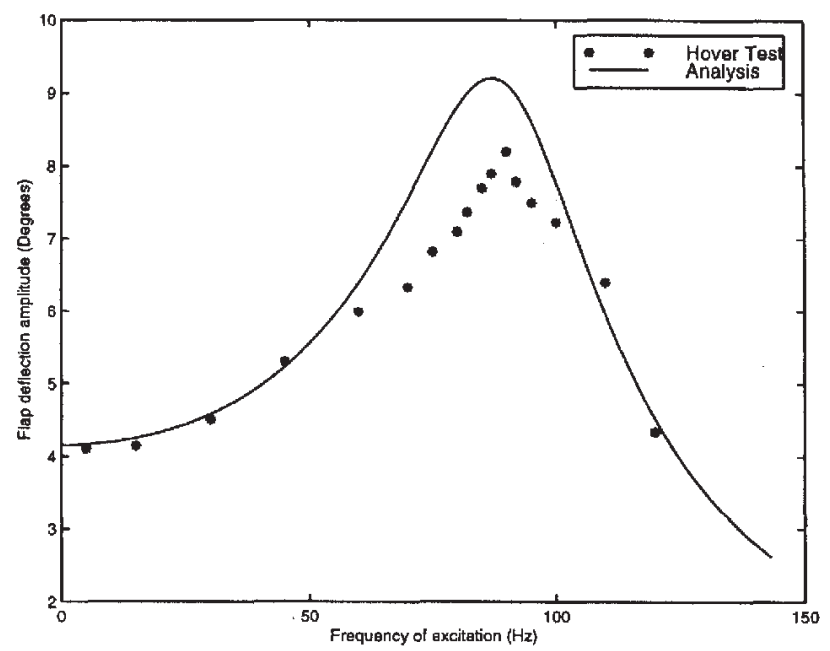

(b)

Figure 13. Hover test of scaled smart-flap rotor blades: (a) side view and (b) variation of flap deflection amplitude with frequency at 900 rpm in the hover test stand (Koratkar and Chopra, 1998).

ing trailing edge flaps. Numerical simulation predicted that, using a flap deflection of $\pm 5^{\circ}$, blade disturbance of the form $\xi(t)=1^{\circ} \cos (\Omega t) \sin ^{2}(\Omega t)$ could be successfully eliminated within 40 blade revolutions. Experimental verification of this hypothesis was presented by Spencer, Sanner, and Chopra (2000). Active trailing edge flaps and active tip twist blade models were tested in the hover stand. Suppression of $1 / \mathrm{rev}$ vibrations and induction of $2 / \mathrm{rev}$ oscillatory loads were successfully demonstrated.

\section{ELECTROMAGNETIC ACTUATED ACTIVE FLAPS}

As an alternative to smart-materials actuation, electromagnetic actuation for rotor blade flaps has recently been explored (Duvernier et al., 2000; Fink et al., 2000). The electromagnetic actuator is based on the interaction between variable electromagnetic fields created in a coil and constant magnetic field generated by permanent magnets. The actuator is based on the Lorenz effect, i.e., it generates an electrodynamic force given by

$$
\mathbf{F}=I(\mathbf{L} \times \mathbf{B})
$$




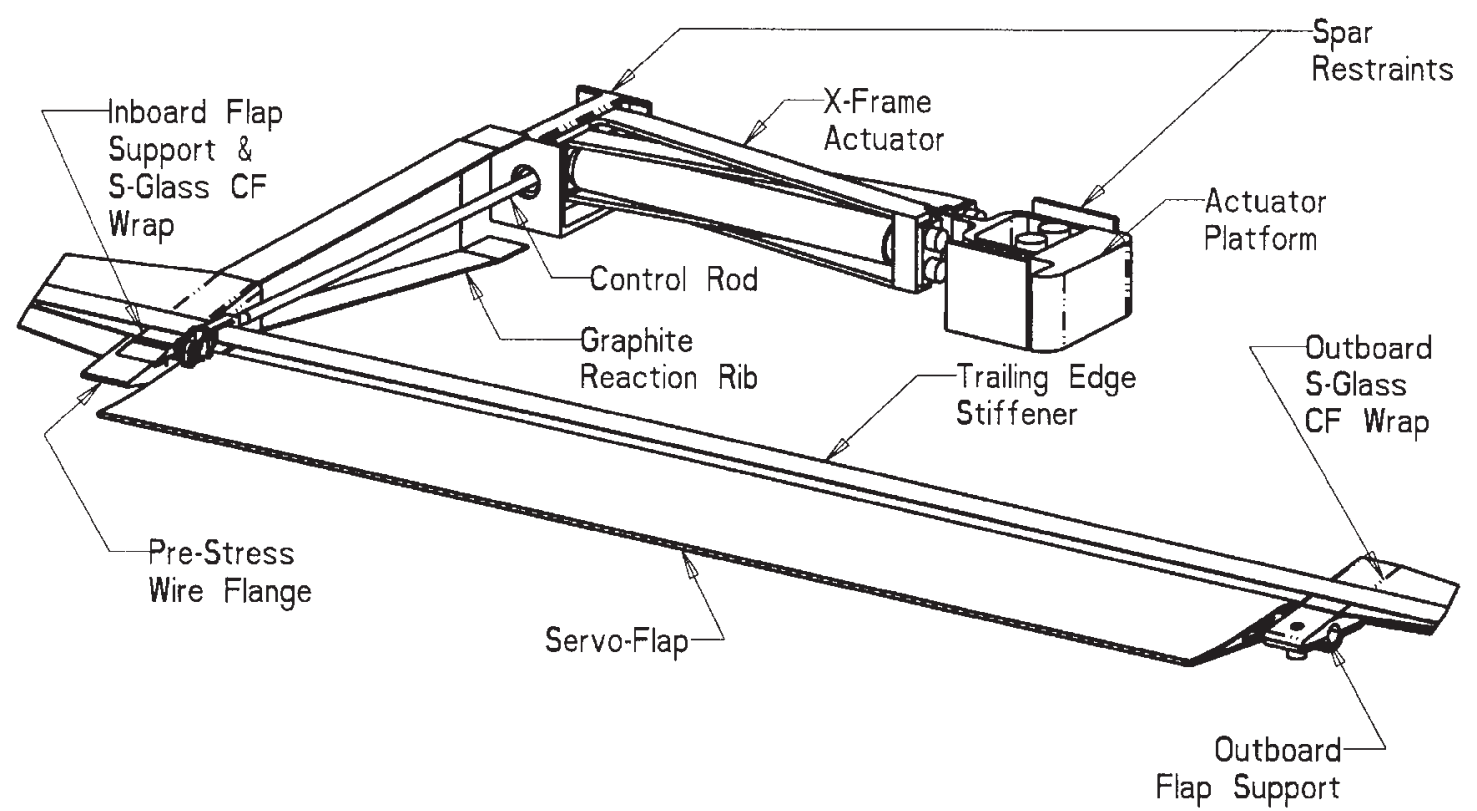

Figure 14. Installation of the X-frame actuator into a $1 / 6$ Mach scale $\mathrm{CH}-47 \mathrm{D}$ rotor blade model (Precht and Hall,1998).

where $\mathbf{F}$ is the force vector, $\mathbf{L}$ is the geometric vector of the electric conductor, $\mathbf{B}$ is the magnetic flux density, and $I$ is the electric current intensity. For B constant, as provided by powerful rare-earth permanent magnets, the resulting force follows the applied current, which can be effectively modulated with modern PWM power electronics.

Duvernier et al. (2000) reported an electromagnetic actuator for rotor blade active flap actuation to be used in the French Dauphin helicopter manufactured by the Eurocopter company. The electromagnetic actuator, is based on a technology patented by the French firm Aerospatiale Matra Missiles. The actuator generates a force proportional with the input electric current, but independent of the stroke position. A bench-top prototype, using a $48 \mathrm{~V}$ dc power supply, was constructed. Its non-optimized weight was $1.4 \mathrm{~kg}$. Static tests were conducted at currents up to $10 \mathrm{~A}$, with quasi-linear behavior observed for current values up to $7 \mathrm{~A}$. At this current value, a force of $250 \mathrm{~N}$ was consistently realized over a \pm 2 $\mathrm{mm}$ stroke. Further dynamic testing proved that these force-stroke characteristics were sustained up to $40 \mathrm{~Hz}$, beyond which a gradual loss of performance was observed. In its present configuration, the electromagnetic actuator provides an energy density of $0.36 \mathrm{~J} / \mathrm{kg}$. Endurance tests were successfully performed $8 \mathrm{~h} /$ day for 9 days, which represents more than 2.5 million cycles. Subsequently, the actuator was integrated into a 1-meter long blade section and made to actuate a 300-mm long trailing edge flap at Eurocopter testing facilities. Simulated flight loads were imposed in the form of centrifugal loads on the blade section and air-jet loads on the flap. Successful dynamic operation of the trailing edge flap through $\pm 5^{\circ}$ up to $30 \mathrm{~Hz}$ was recorded. Beyond $30 \mathrm{~Hz}$ the response starts to increase due to the effect of a $80-\mathrm{Hz}$ mechanical resonance.
Fink et al. (2000) reported the development of an electromagnetic actuator for a rotor blade trailing-edge flap named Heliflap $^{\mathrm{TM}}$. The actuator-flap system was designed to achieve individual blade control in a swashplateless rotor. A prototype was constructed and tested on a full-scale $\mathrm{OH}-58 \mathrm{D}$ teetering rotor whirl stand. The 6-in by 24 -in prototype actuator was incorporated into the blade D-spar and mechanically connected to a trailing edge flap (24-in long, 5.96-in chord, flap-to-blade chord ratio 0.459). The net installed weight for the non-optimized prototype was $9.6 \mathrm{lb}$. Bench testing demonstrated $0.356 \mathrm{ft}-\mathrm{lb} / \mathrm{A}$ static torque, $\pm 8^{\circ}$ deflection, and dynamic operation up to $37 \mathrm{~Hz}$. Whirl testing of up to $81 \%$ of nominal rotor speed $\left(81 \% N_{R}\right)$ demonstrated $\pm 6^{\circ}$ deflection at $21 \mathrm{~Hz}$ requiring $\pm 16 \mathrm{~A}$ and an average electrical power of $220 \mathrm{~W}$ (Figure 17). Frequency response curves for various rotor speeds indicate a mechanical resonance at $16 \mathrm{~Hz}$ at $0 \%$ $N_{R}$ that moved towards $20 \mathrm{~Hz}$ for $56 \% N_{R}$, and possibly $21 \mathrm{~Hz}$ for $81 \% N_{R}$ Outside resonance, the deflection was lower, typically $\pm 4^{\circ}$. Of considerable interest during these experiments was the thermal management of the heat dissipation occurring in the electromechanical actuator. Heat transfer modeling at $192^{\circ} \mathrm{C}$ operating temperature indicated that $8.1 \mathrm{~kW}$ could be transferred through the blade aluminum skin, and an additional $1.9 \mathrm{~kW}$ radially through conduction.

\section{FULL-SCALE SMART ROTOR BLADE FLAP EXPERIMENTS}

A federally funded program for full-scale implementation of smart materials actuation rotor technology (SMART) is under way at Boeing Mesa, Arizona. Straub (1993) analyzed the feasibility of using active materials actuators for rotor blade control. Straub and Merkley (1995) presented a design study for the implementation of a smart rotor-blade flap on 


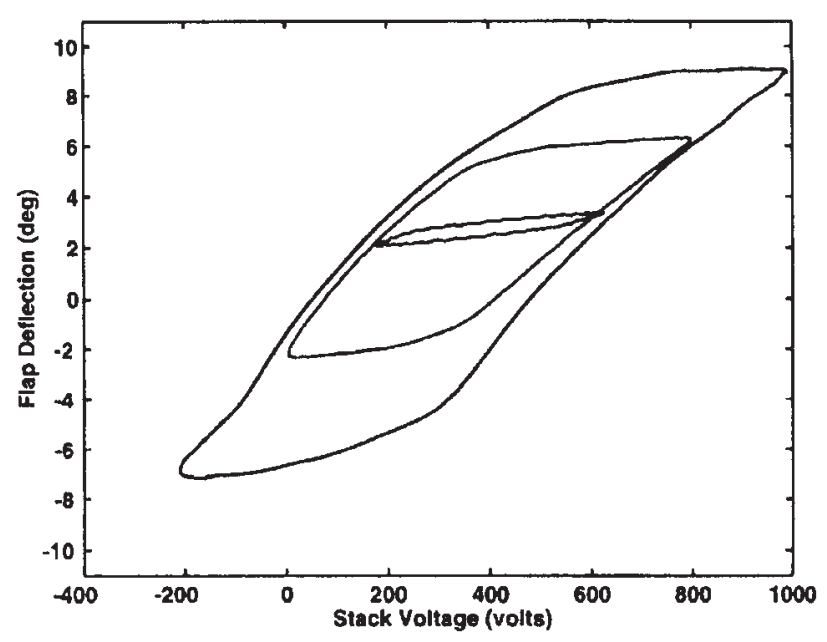

(a)
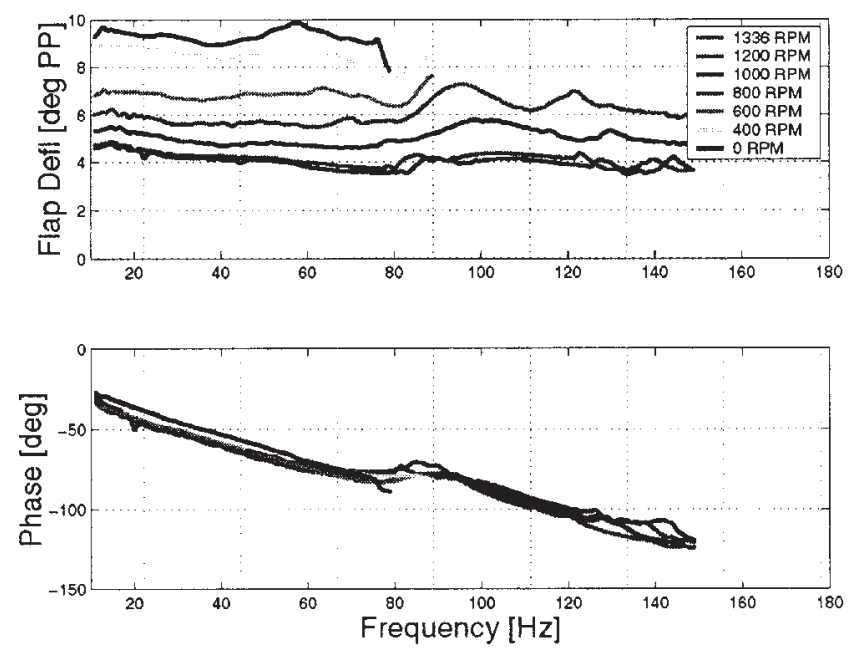

(b)

Figure 15. Deflection of the X-frame actuated trailing-edge flap in the 1/6 Mach scale $\mathrm{CH}-47 \mathrm{D}$ rotor blade model: (a) response for $3 \mathrm{~Hz}$ excitation at various voltage levels, zero rpm (Hall and Prechtl, 1999) and (b) frequency response at maximum voltage excitation, in hover tests at various rpm (Straub, 1999).

the AH-64 Apache helicopter. In a gradual approach, the full-scale proof-of-concept demonstration is initially planned on the MD 900 bearingless rotor (Straub and King, 1996). After successful proof of concept demonstrations, future applications on AH-64, V-22, RAM-66 and JTR are envisaged. The conceptual design calls for a trim tab for in-flight blade tracking and an active control flap for noise and vibration reduction, as shown in Figure 18 (Straub and King, 1996).

A prototype flap actuator with a two-stage amplification and bi-axial operation was constructed and tested (Straub, 1999). The actuator contained two parallel piezo-stack columns working out-of-phase in a push-pull mode. The 2-stage amplification resulted in a total stroke amplification of about 10:1. Output displacements of up to $0.4 \mathrm{~mm}$ were measured under simulated load conditions in a $0-40 \mathrm{~Hz}$ bandwidth.

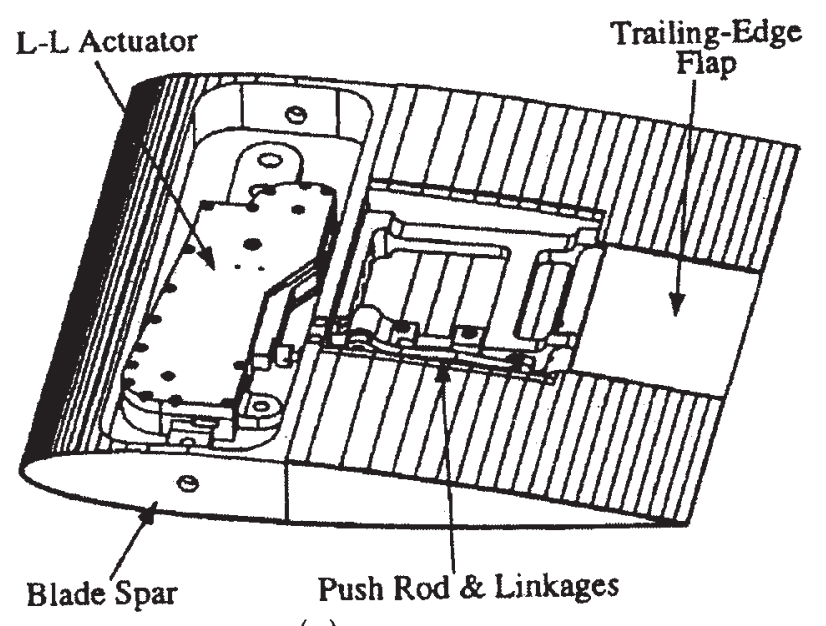

(a)

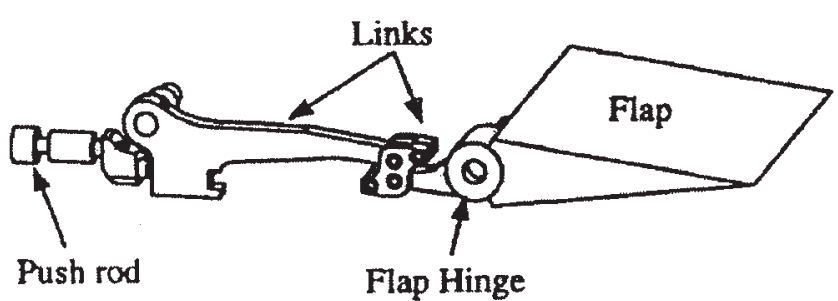

(b)

Figure 16. (a) Schematic of the blade incorporating the $L-L$ actuator and trailing edge flap and (b) details of the linkage mechanism (Koratkar and Chopra, 2000).

The stack heat transfer was studied under sustained $40-\mathrm{Hz}$ operation. Temperature stabilization at $+22^{\circ} \mathrm{C}\left(40^{\circ} \mathrm{F}\right)$ above ambient was observed, thus indicating that long-term sustained operation is feasible. The actuator was also successfully subjected to environmental qualification tests consisting of shake testing (29 g @ 2/rev) and spin testing (814 g). The total actuator weight was $\sim 0.75 \mathrm{~kg}$ (1.65-lb). Presently, the SMART rotor program team consists of Boeing, Massachusetts Institute of Technology (MIT), University of California at Los Angeles (UCLA), and University of Maryland. Support to the program is also being offered by NASA Ames $(40 \times 80$-ft wind tunnel tests), Rockwell Science Center (RSC), and TRS Ceramics, Inc.

A new displacement amplification principle, the double $\mathrm{X}$-frame (2-X) concept has been adopted, fabricated, and tested (Figure 19). The 2-X prototype demonstrated 1-mm stroke and successfully sustained environmental and spin tests (Hall et al., 2000). Separate piezo-stacks selection tests conducted at UCLA identified TRS and RSC piezo-stacks with higher energy densities $(\sim 0.555 \mathrm{~J} / \mathrm{kg})$ at optimal preload values (14 MPa). When incorporated into the $2-\mathrm{X}$ actuator, such piezo-stacks are predicted to exceed the $2 \mathrm{deg}$. design specification (Straub, 1999). Up to $3^{\circ}$ flap-authority is predicted with high voltage stacks, and $4^{\circ}$ with single-crystal stacks. 

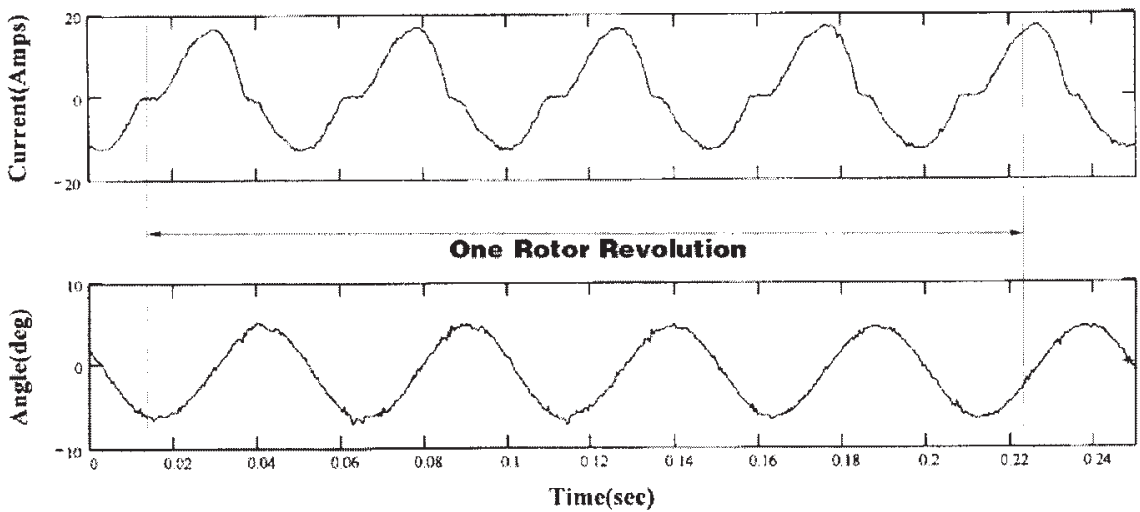

(a)

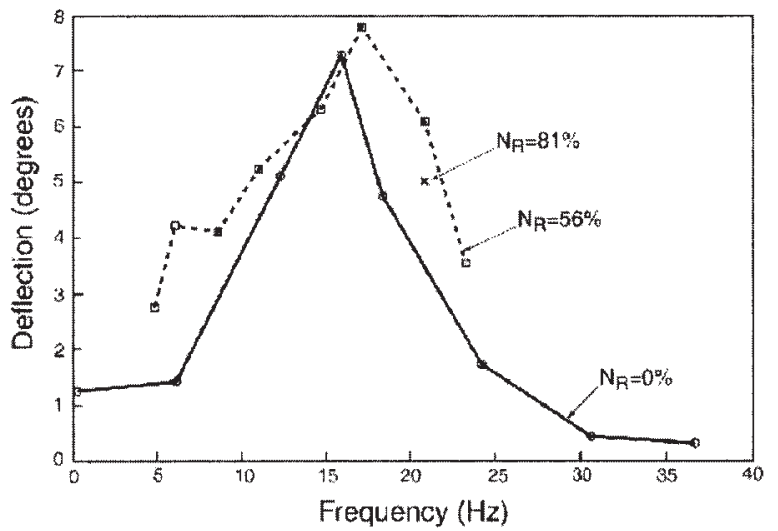

(b)

Figure 17. Details of the electromagnetic Heliflap whirl stand tests: (a) time histories of electric current and corresponding flap displacement at $\mathrm{N}_{\mathrm{R}}=81 \%$ rotor speed and (b) frequency variation of maximum flap deflection at various rotation speeds (Fink et al., 2000).

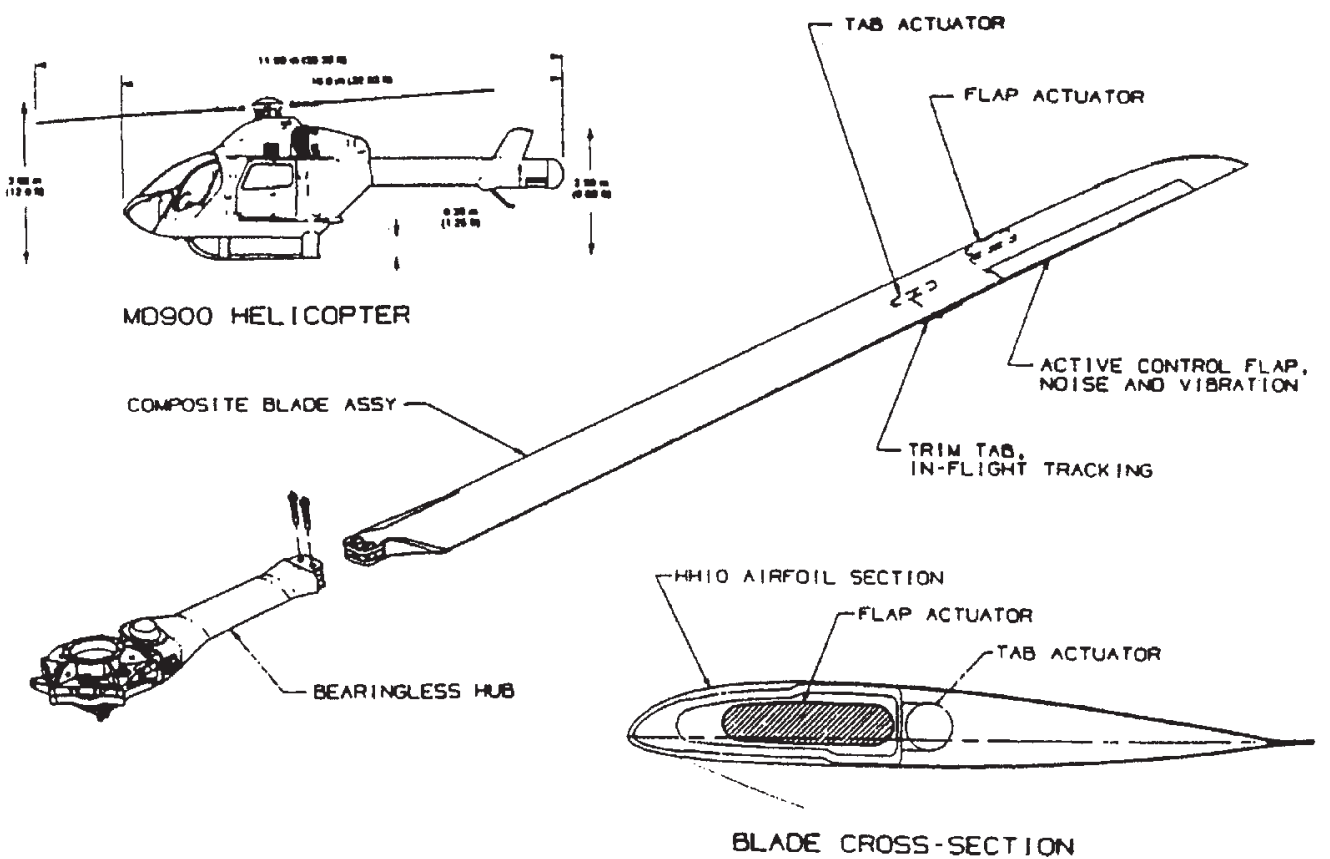

Figure 18. MD 900 helicopter hingeless blade displaying the planned trim tab for in-flight tracking and active control flap for noise and vibration reduction (Straub and King, 1996). 


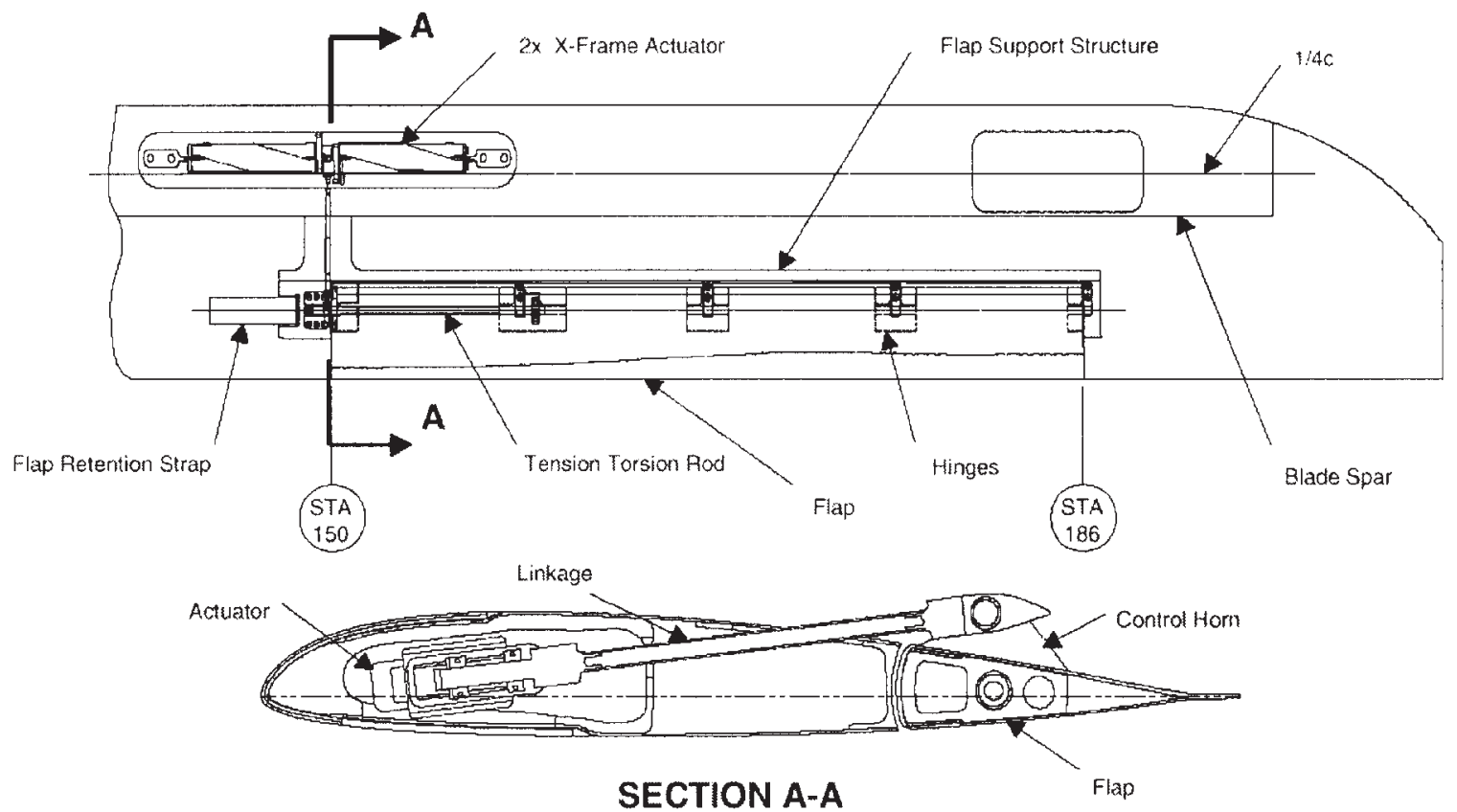

Figure 19. Flap actuation integration for the SMART blade prototype (Straub, 1999).

The trim tab effort has also made considerable progress (Kennedy, Straub et al., 2000). A Shape Memory Alloy (SMA) actuator has been designed, built, and bench tested. The actuator has a bi-axial construction, with two parallel antagonistic SMA torsion tubes realizing a bi-directional actuation capability that can apply a $\pm 7.5^{\circ}$ deflection on the trim tab [Figure 20(a)]. An SMA locking mechanism (brake) was installed to maintain the set-point position. The SMA brake is normally locked, and positive action is required to activate and unlock it before actual tab movement can be achieved. After the tab is moved, the brake locks back in place [Figure 20(b)].

\section{FIXED WING AIRCRAFT APPLICATIONS}

\section{Flutter Suppression Studies}

Heeg (1993) reported an analytical and experimental investigation of flutter suppression of a fixed wing by piezoelectric actuators. The experimental studies were performed in Flutter Research and Experimental Device (FRED) at NASA Langley Research Center. FRED is an open-circuit table-top wind tunnel with a 6 -in $\times 6$-in acrylic glass test section and $1500 \mathrm{in} / \mathrm{sec}$ maximum speed. The test article consisted of four components: a flexible mount system, a rigid wing, piezoelectric plate actuators, and a strain gauge bridge (Figure 21). The test article was designed for a predicted plunge mode flutter condition at $560 \mathrm{in} / \mathrm{sec}$. The flexible mount system had two plunge spring tines and one pitch spring. Two 1.5 -in $\times 1$-in piezoelectric wafer actuators were installed on one of the plunge spring tines near its root. The wafers were bonded to opposing sides of the plate to form a bimorph actuator. Strain feedback was acquired through a strain gauge bridge mounted on one of the spring tines. A digital control algorithm was implemented on a PC. The control signal was sent to an operational amplifier (25-times amplification) with a maximum voltage of $\pm 80 \mathrm{~V}$ (Figure 22). Experimental tests identified the open loop flutter at 580 $\mathrm{in} / \mathrm{sec}$. Closing the control loop increased the flutter speed to $697 \mathrm{in} / \mathrm{sec}$, i.e., by $20 \%$.

\section{PARTI Program}

The ability of induced-strain actuated adaptive wings to control dynamic aeroelastic phenomena was demonstrated through the Piezoelectric Aeroelastic Response Tailoring Investigation (PARTI). Wind tunnel tests in NASA Langley Transonic Dynamic Tunnel with a 4-ft long semi-span wing model successfully demonstrated flutter suppression and gust loads alleviation (McGowan et al., 1998). The wing model (Figure 23) consisted of a composite plate (graphite epoxy face sheets with aluminum honeycomb core) with 36 piezoelectric wafers surface bonded to each side of the plate. In addition, 14 resistance strain gauges and 4 accelerometers were used. The 36 piezoelectric wafers were arranged into 15 groups to be independently assigned actuator or sensor functions. Both active aeroelastic control and active/passive shunt damping were investigated. For active aeroelastic control, the power required to achieve effective control-law implementation was monitored. The maximum power consumption was found when the structure was perfectly controlled.

This maximum power consumption was shown to be a function of material and geometric properties of the piezo- 


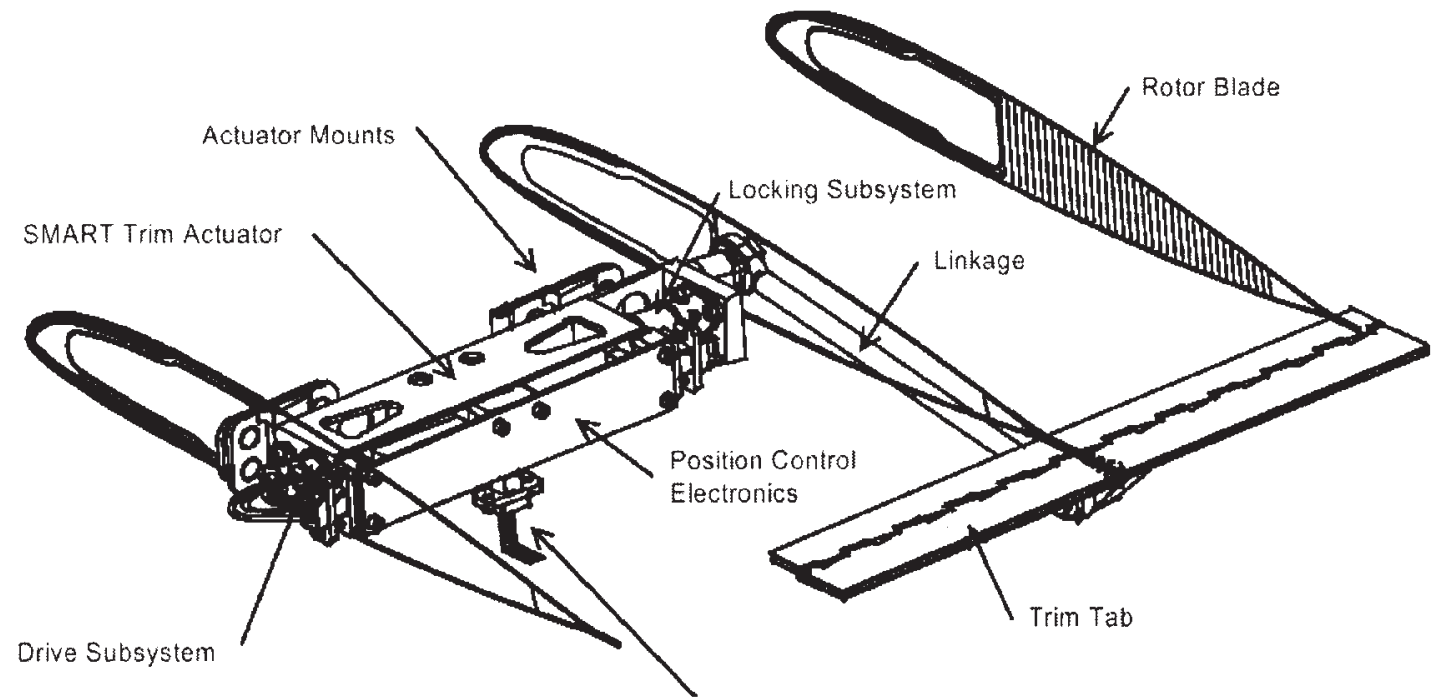

(a)

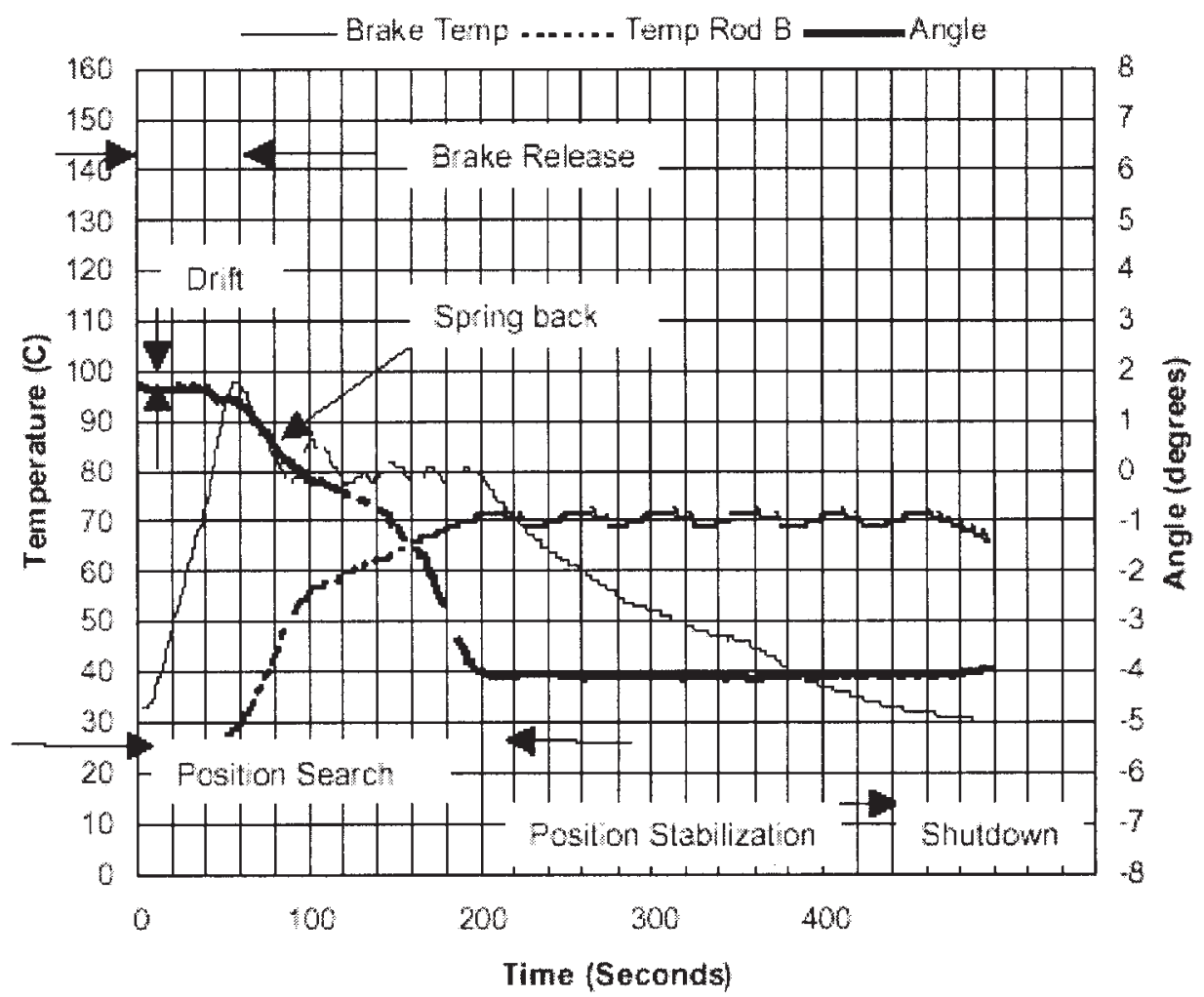

(b)

Figure 20. SMA actuator for full-size trailing edge flap experiment: (a) construction and installation schematics and (b) operation diagram recorded during a $+2^{\circ}$ to $-4^{\circ}$ static bench test (Kennedy, Straub, et al., 2000). 


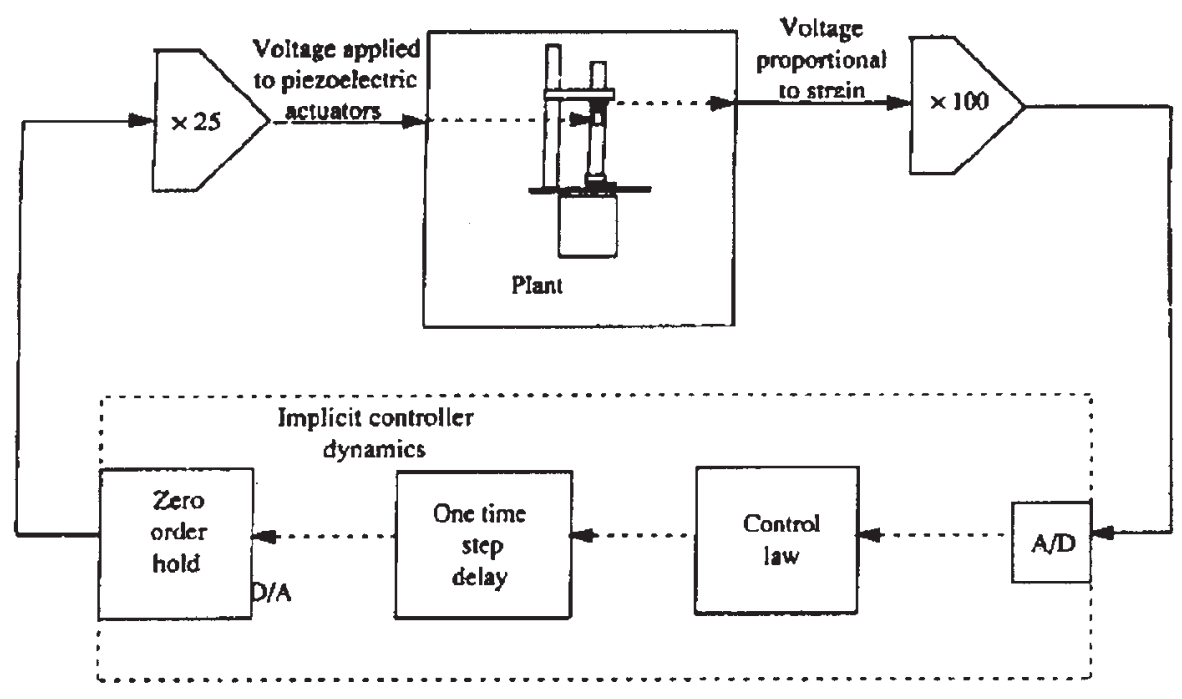

(a)
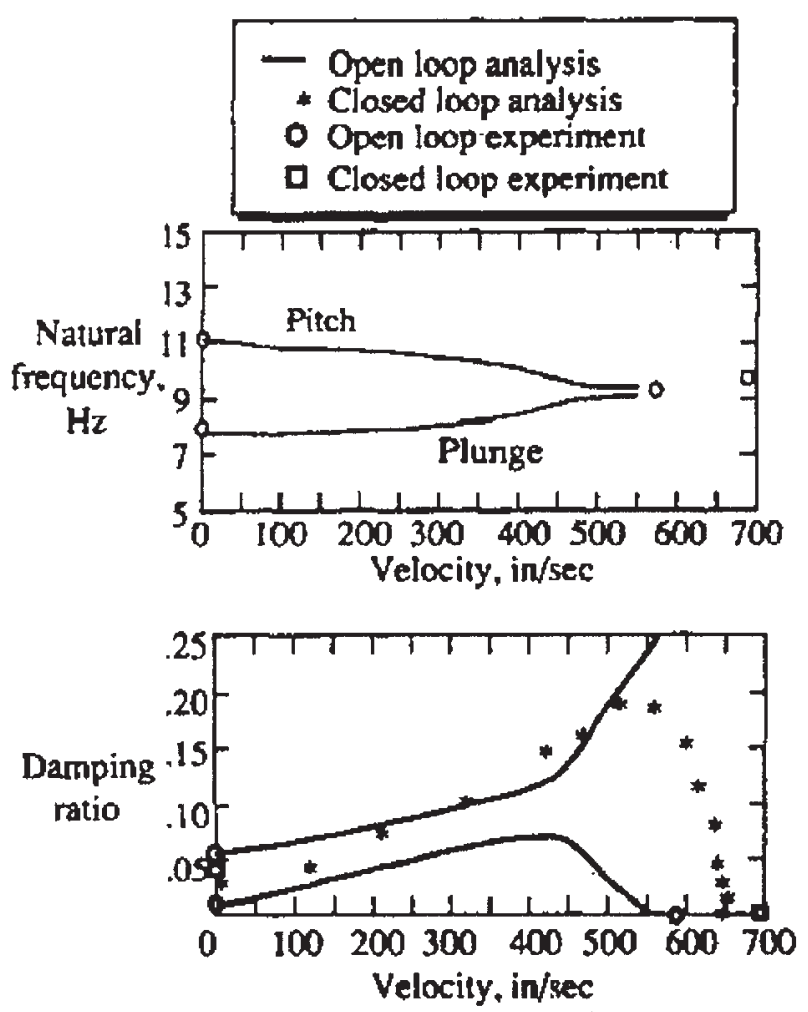

(b)

Figure 21. Flutter suppression experiments at NASA Langley Research Center: (a) block diagram of closed loop control system for the induced-strain actuation flutter suppression experiment and (b) experimental results demonstrated a $20 \%$ increase in test article flutter speed from $580 \mathrm{in} / \mathrm{sec}$ to $697 \mathrm{in} / \mathrm{sec}$ (Heeg, 1993). 


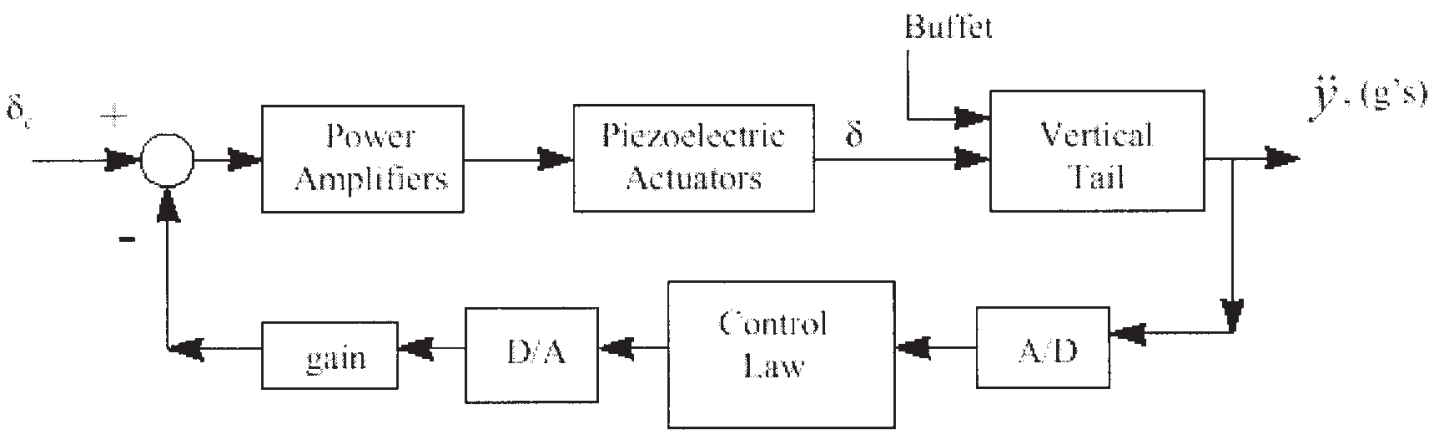

Figure 22. Schematic of the active control system using piezoelectric actuators to achieve buffet suppression (Moses, 1997a).

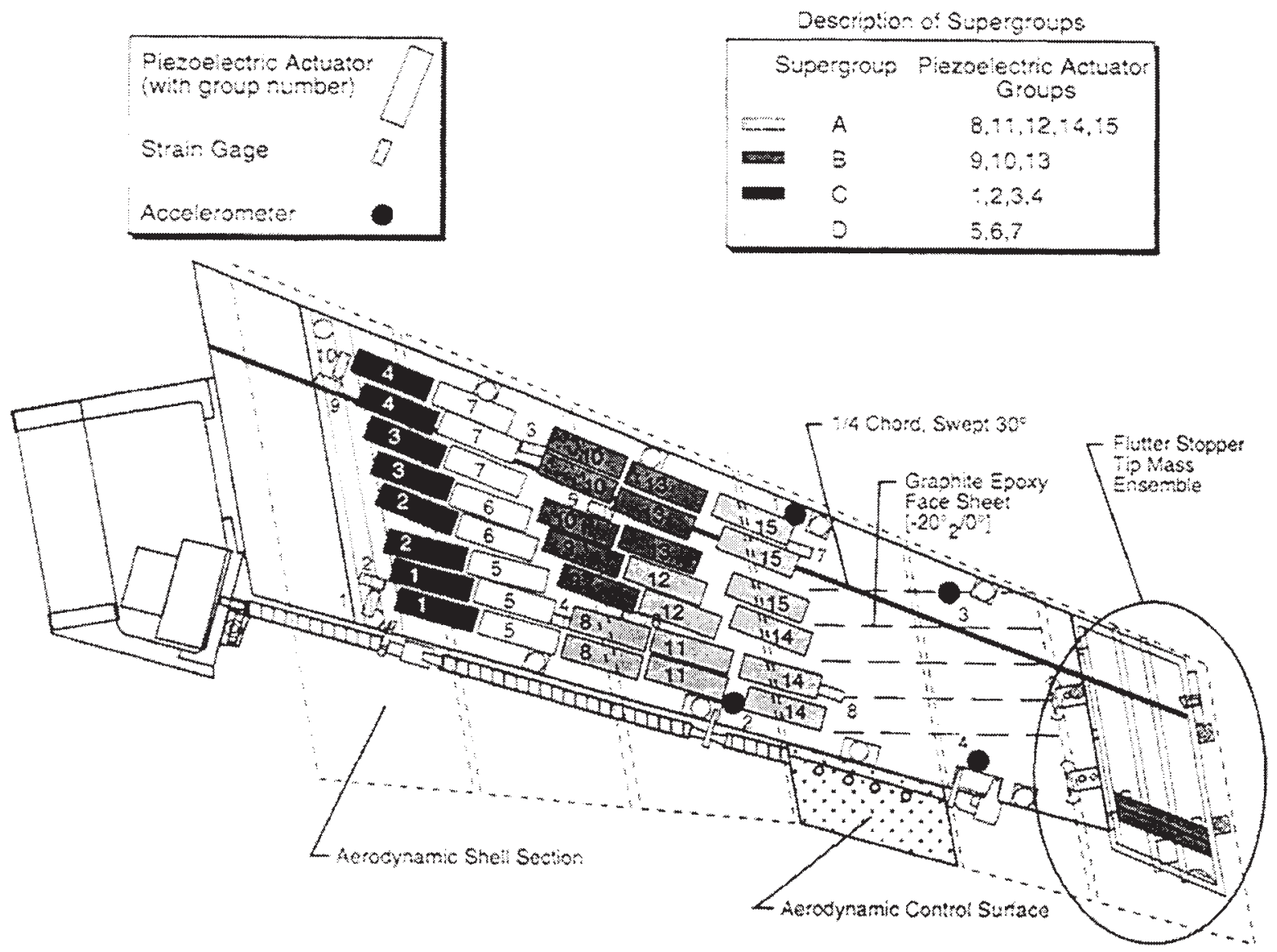

Figure 23. Piezoelectric Aeroelastic Response Tailoring Investigation (PARTI) scaled wing for wind-tunnel tests (McGowan et al., 1998). 


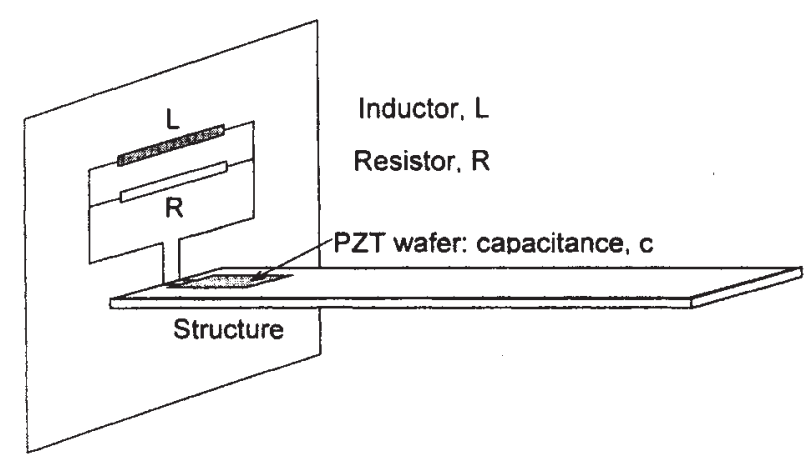

Figure 24. Parallel shunt circuit for vibration control.

electric actuator and not to depend on the complex system dynamics. Studies were also performed to identify the optimal actuator activation configuration to minimize the power requirements. The tests proved that $12 \%$ increase in flutter dynamic pressure and $75 \%$ reduction of gust bending moment are achievable. Further investigations were focused on the use of passive/active shunts (Figure 24) connected to the piezoelectric wafers. The active shunts utilize tuning methods to eliminate the critical frequencies.

\section{ACROBAT Program}

The feasibility of using active piezoelectric control to alleviate vertical tail buffeting was investigated under the Actively Controlled Response of Buffet Affected Tails (ACROBAT) program (Moses, 1997a,b). Tail buffeting is a significant concern from fatigue and maintenance standpoints. During the ACROBAT program, active materials solutions to buffet problems were studied on 1/6-scale rigid full-span model of the F/A-18 aircraft tested in the Langley Transonic Dynamics Tunnel (TDT). The piezoelectric wafer actuators were placed in opposing pairs on both surfaces of the vertical tails (Figure 25). The port vertical tail was equipped with surface-bonded piezoelectric wafer actuators, while the starboard vertical tail had an active rudder and other aerodynamic devices. Buffeting alleviation control laws aimed at reducing the fin tip acceleration were imposed [Figure 26(a)]. The tunnel was run at atmospheric pressure and $14-\mathrm{ft} / \mathrm{sec}$ airspeed. The F/A-18 model was tested at up to $37^{\circ}$ angles of attack. Constant-gain active control of the piezoelectric wafer actuators resulted in reduction of the root bending moment [Figure 26(b)]. The power spectral density of the root strains at the vertical-tail first bending resonance was reduced by as much as $60 \%$, while the corresponding root mean square (rms) values were reduced by up to $19 \%$. In achieving these results, both active rudder and piezoelectric actuators seem to be similarly effective.

The SIDEKIC program (Scaling Influences Derived from Experimentally-Known Impact of Controls) followed the ACROBAT program (Moses, 1999). To obtain better scaling similarity, a thin-walled construction of the wind tunnel model was adopted, while the piezoelectric actuators were

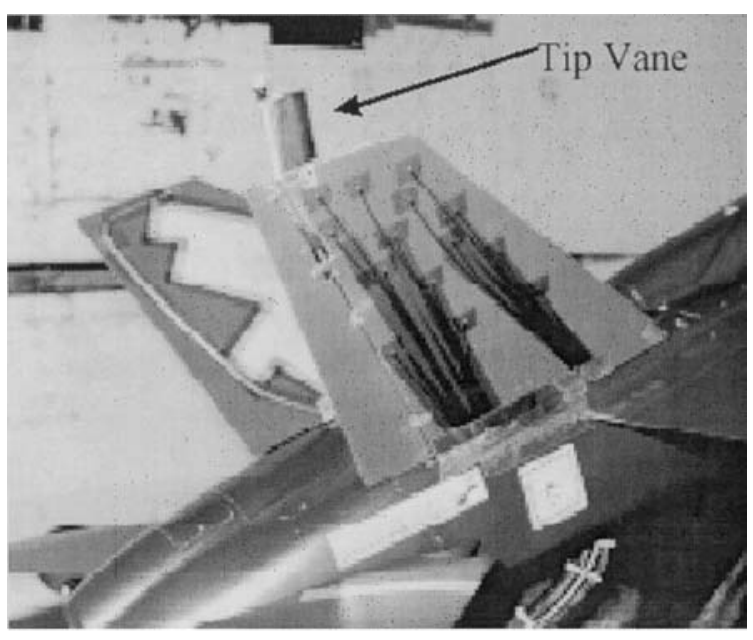

(a)

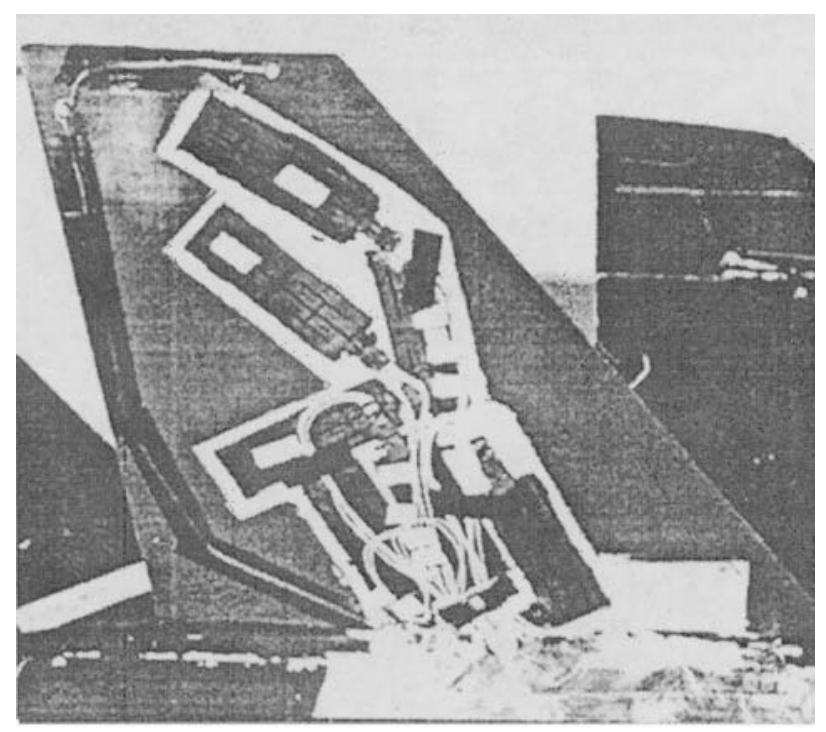

(b)

Figure 25. ACROBAT program: (a) 1/6-scale rigid full-span wind-tunnel F/A-18 rigid model was instrumented with piezoelectric wafer actuators and other vibration alleviation devices and (b) detail of piezoelectric actuator installation (Moses, 1997b).

made more numerous and of smaller size. A blended system approach was adopted where by the active rudder was aimed at reducing the first bending resonance $(\sim 17 \mathrm{~Hz})$ whereas the piezoelectric wafer actuators were focused on the first torsional resonance $(\sim 58 \mathrm{~Hz})$. The successful reduction of both resonances is illustrated in Figure 27. The ACROBAT and the SIDEKIC programs demonstrated that control of tail buffet vibrations could be achieved with piezoelectric actuators. These programs opened the way towards the full-scale experimentation of this novel concept.

\section{Active Suppression of Tail Buffeting}

A full-scale experimental program to investigate the ac- 


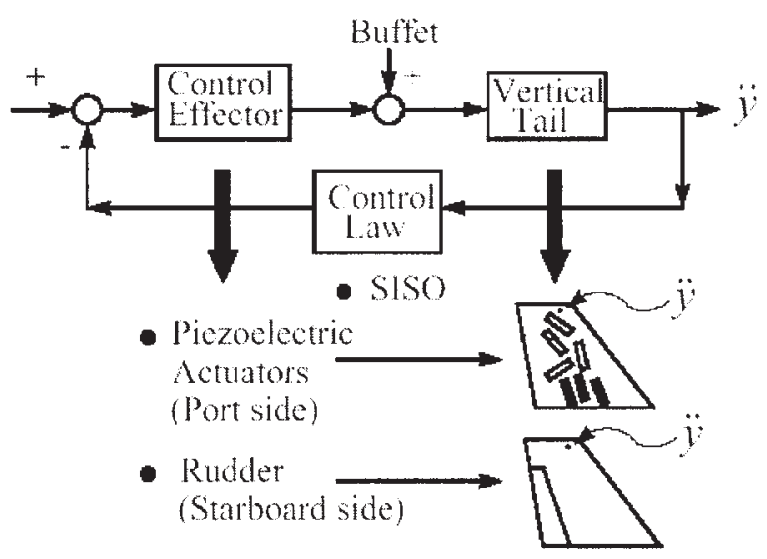

(a)

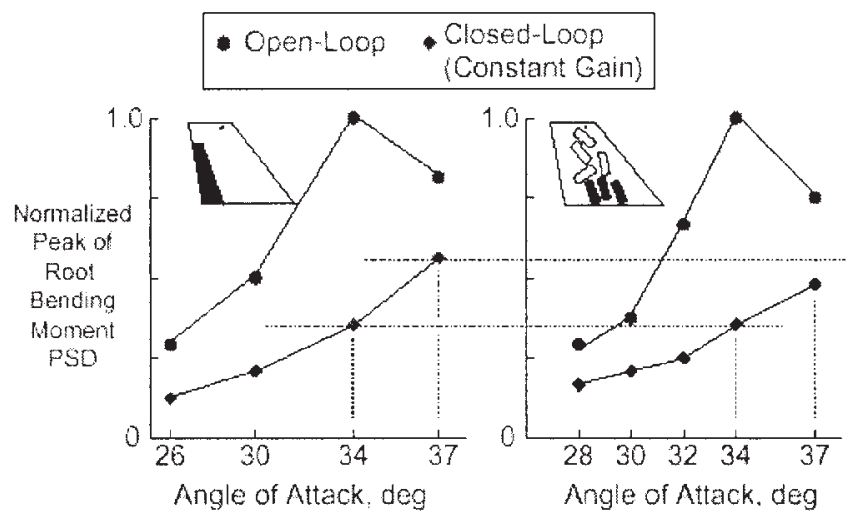

(a) Rudder Results

(b) Piezo Results

(b)

Figure 26. ACROBAT tail buffet alleviation experiments: (a) single-input single-output (SISO) control law design for active rudder and piezoelectric wafers excitation and (b) power spectrum density (PSD) peak values for the root bending moment at the first bending resonance (Moses, 1997b).

tive suppression of vertical tail buffeting vibrations in the F/A-18 aircraft is currently under way in a joint US/Australia/Canada effort (McGowan et al., 1998; Hopkins et al. 1998; Moses, 1999). The full-scale test article is the vertical tail on a no-longer flight-worthy fighter aircraft that is tested in the International Follow-On Structural Testing Project rig at the Aeronautical and Maritime Research Laboratory (AMRL) in Melbourne, Australia [Figure 28(a)]. Preliminary ground tests under simulated vibrations indicated that reduction of the peak bending moment response on the fullscale aircraft is feasible [Figure 28(b)]. Due to difficulties related to the non-linear response of the load-simulation shaker and the construction of the feedback controllers and amplifiers (Moses, 1999), the vibration alleviation targets were not quite reached during these full-scale experiments [Figure 28(c)]. At present, new ground and flight-test experiments that will incorporate technology advances in amplifier and

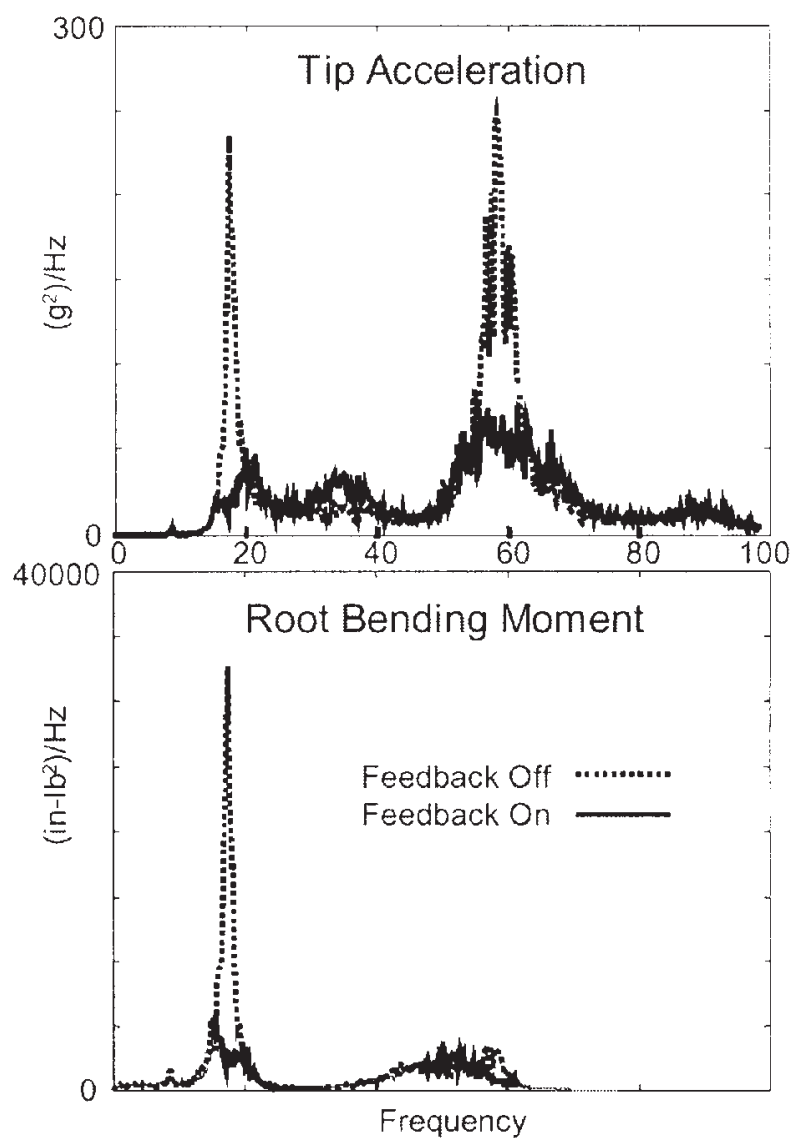

Figure 27. PSD plots showing acceleration and bending moment suppression of both bending and torsional resonances in the SIDEKIC program (Moses, 1999).

controller design, as well as results from the SIDEKIC program are planned (Moses, 1999).

Simpson and Schweiger (1998) conceptualized the use of piezo-electric damping for active suppression of buffeting vibration in the vertical tail of fighter aircraft. Manser et al. (1999) describe proof-of-concept experiments performed on a $2000-\mathrm{mm} \times 700-\mathrm{mm} \times 156-\mathrm{mm}$ fin-box specimen at Daimler-Chrysler Aerospace in Germany. The fin box specimen was constructed from aluminum spars and carbon fiber composite skins of thickness varying from 14-mm at the root to $3-\mathrm{mm}$ at the tip. The first natural frequency of the fin-box specimen was designed to correspond to that of a real aircraft (approximately $18 \mathrm{~Hz}$ ). Custom-made piezoelectric wafer actuators with a voltage range of $\pm 200 \mathrm{~V}$ were applied to the carbon fiber composite skins (42 actuators in 4 groups per side).

Four custom-made high-power switching amplifiers of 2 $\mathrm{VA}$ rating $(10 \mathrm{~A}$ at $200 \mathrm{~V}$ ) over the $200 \mathrm{~Hz}$ bandwidth were employed. Modal response tests identified the first bending mode at $18.06 \mathrm{~Hz}$ with $0.44 \%$ critical damping. Open-loop tests proved that, at the first bending resonance, a maximum tip response of $13.4 \mathrm{~mm}$ could be attained. Closed loop tests were performed with a variable-gain analog feedback amplifier [Figure 29(a)]. The closed-loop tests demonstrated critical damping increase from $0.44 \%$ to $3.70 \%$ as the feedback 


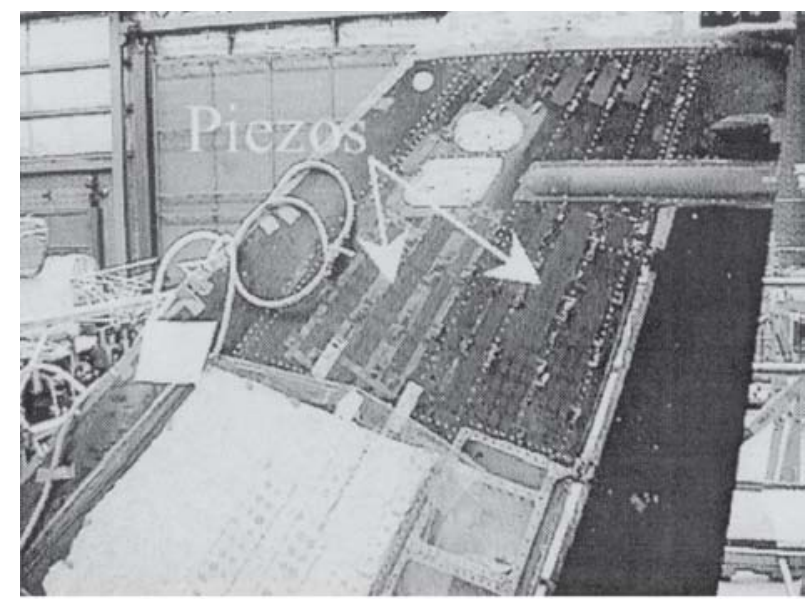

(a)

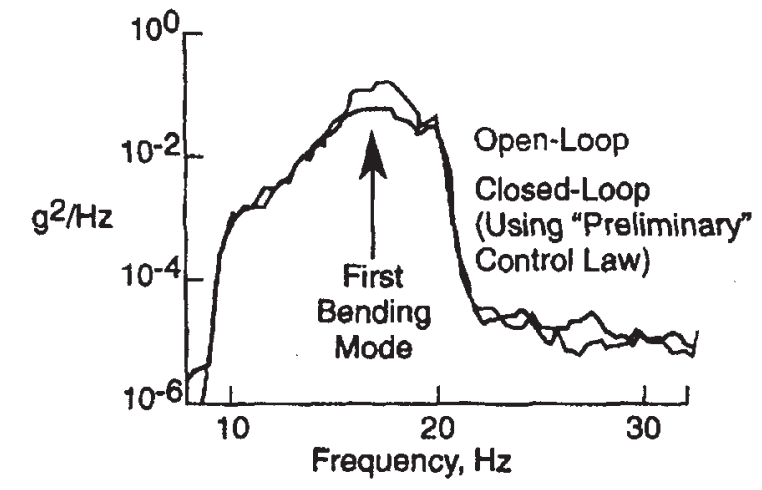

(b)

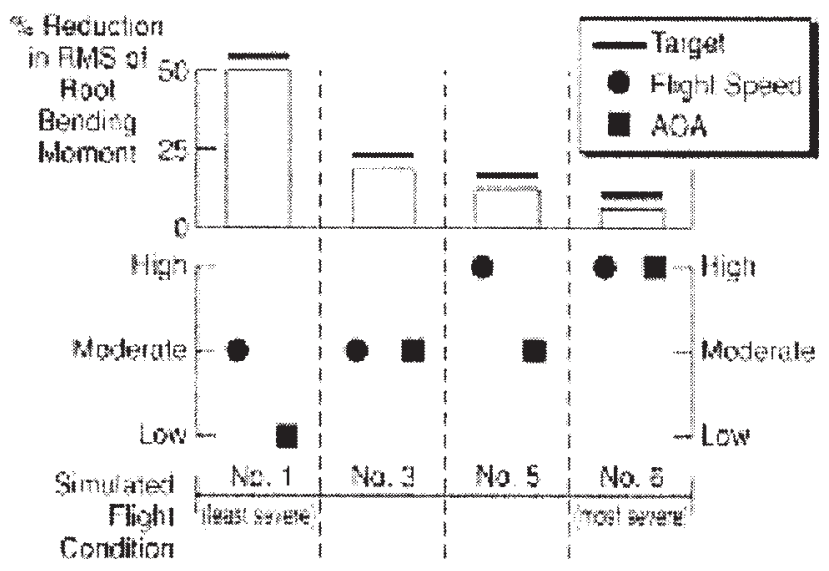

(c)

Figure 28. (a) Piezoelectric actuators bonded on the vertical tail (Moses, 1999), (b) power spectral density of acceleration measured on the vertical tail tip near the trailing edge on F/A-18 aircraft during initial ground tests (McGowan et al., 1998) and (c) achieved reduction in rms root-bending moment during simulated ground tests for various flight speed and angle of attack (AOA) values (Moses, 1999).

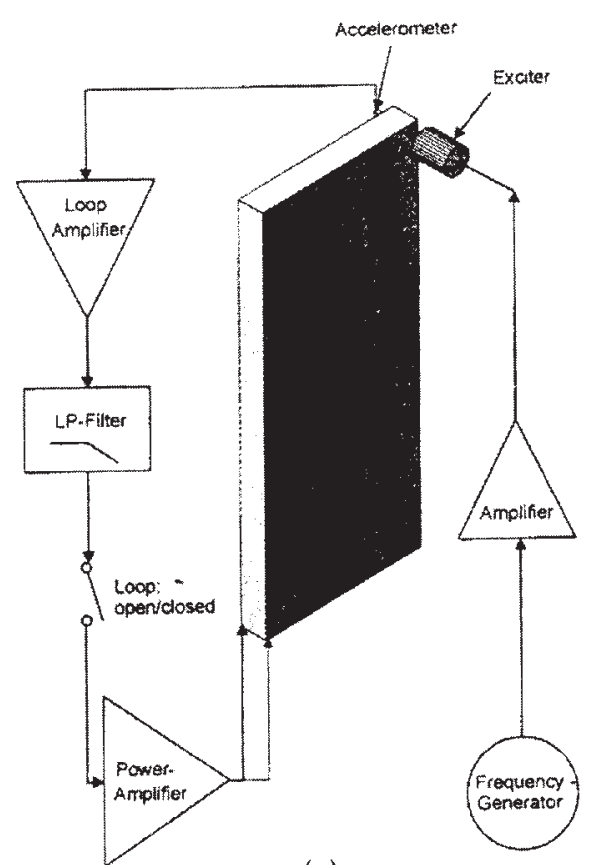

(a)

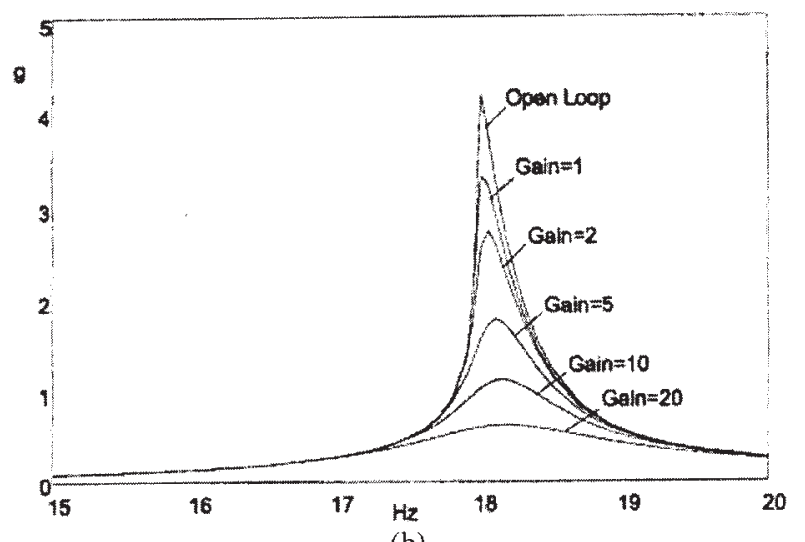

(b)

Figure 29. Tail buffet suppression tests performed by Daimler-Chrysler Aerospace on a full-scale fin-box specimen: (a) schematic (LP = low pass) and (b) results (Manser et al., 1999).

gain was varied from 0 to 20 [Figure 29(b)]. A comprehensive analysis of the design and fabrication issues associated with transferring these proof-of-concept results to operational aerospace structures was presented by Durr et al. (1999).

\section{Active Suppression of Skin Panel Vibration}

Acoustically induced skin panel vibrations due to engine noise and flow turbulence can lead to early fatigue failures and are a major maintenance concern. Larson et al. (1998) describe the use of piezoceramic wafer actuators for active vibrations suppression of an acoustically excited B-1B aircraft skin panel. A 24 -in by 10 -in highly curved 0.080 -in thick panel on the TDS B-1B test bed aircraft was instru- 
mented with PZT wafer actuators, 14 for symmetric actuation, and 8 for anti-symmetric actuation. Each actuator has a 1 -in by $1 / 3$-in area. The control laws were processed on a Motorola 68040 microprocessor chip. The target of the active control experiment was to stabilize the modes below $1500 \mathrm{~Hz}$ and control the modes in the range $400-800 \mathrm{~Hz}$. The system successfully reduced the fundamental panel-vibration modes by $79 \%$, for the takeoff conditions, and about $46 \%$, for transonic flight conditions. The higher modes were reduced by $25 \%$.

\section{CONCLUSIONS}

Smart-materials induced-strain actuation (ISA) for aeroelastic and vibration control have evolved from laboratory scale proof-of-concept demonstrations to full-scale helicopter and airplane implementation. So far, the research efforts have channeled on two approaches: (1) distributed/continuous induced-strain actuation with embedded/distributed active materials; (2) discrete/pointwise excitation using active-material based actuators. Distributed induced-strain actuation has only had partial success due to the high inherent stiffness of traditionally designed structures. Consequently, experimental results, e.g., induced-strain twists, have not produced sufficient twist actuation. To achieve better results, a multidisciplinary optimization approach, including ISA effects, needs to be taken (Wilkie, Belvin, and Park, 1998; Schweiger et al., 1999). Discrete actuation has been more successful, partly due to the separation of variables, and partly because it lends itself easily to retrofitting existing structures. In discrete actuation, the major challenge is to amplify the patently small active-material ISA response in order to create usable actuator stroke output. A number of ingenious solutions have been developed, especially for helicopter applications.

The upcoming challenges will be connected with the system integration of the smart materials devices into the overall weight and power balance of the aircraft. Significant power supply, airworthiness, and reliability problems are expected. Among them, two are more acute: (1) the development of compact onboard power amplifiers capable of handling the large reactive power requirement of the piezoelectric system; and (2) the utilization of the full frequency bandwidth capability of the piezoelectric devices through frequency devolution and peak energy per cycle magnification.

\section{ACKNOWLEDGEMENTS}

The authors gratefully acknowledge the financial support of the US Department of Defense through Army Research Office Grant \#DAAD19-00-1-0017 and South Carolina Army National Guard Cooperative Agreement F 168, and of the US Department of Energy through Sandia National Laboratories, \#BF-0133.

\section{REFERENCES}

Barrett, R., 1993. "Aeroservoelastic DAP Missile Fin Development," Smart Materials and Swactures, Vol. 2, pp. 55-65.

Barrett, R. and Stutts, J., 1997. "Design and Testing of a 1/12th-Scale Solid State Adaptive Rotor," Smart Materials and Structures, Vol. 6, pp. 491-497.

Barrett, R., Frye, P. and Schliesman, M., 1998. "Design, Construction, and Characterization of a Flightworthy Piezoelectric Solid State Adaptive Rotor," Smart Materials and Structures, Vol. 7, pp. 422-431.

Bernhard, A. P. F. and Chopra, I., 1998. "Hover Testing of Active Blade-Tips Using a Piezo-lnduced Bending-Torsion Coupled Beam," Journal of Intelligent Material Systems and Structures, Vol. 9, No. 12, pp. 963-990.

Cesnik, C. E. S., Shin, S. J., Wilkie, W. K., Wilbur, M. L. and Mirick, P. H., 1999. "Modeling, Design, and Testing of the NASA ARMY/MIT Active Twist Rotor Prototype Blade," 55th Annual Forum of the American Helicopter Society, Montreal, Canada, May 25-27.

Cesnik, C. E. S. and Shin, S. J., 1999. "On the Twist Performance of a Multiple-Cell Active Helicopter Blade," 8th ARO Workshop on Aeroelasticity of Rotorcraft Systems, Penn State University, October $18-20$.

Chen, P. C. and Chopra, I., 1997. "Wind Tunnel Test of a Smart Rotor Model with Individual Blade Twist Control," SPIE Vol. 3041, pp. 217-229.

Chopra, I., 2000. Private communication.

Chopra, I., 1997. "Status of Application of Smart Structures Technology to Rotorcraft Systems," Innovation and Rotorcraft Technology, Royal Aeronautical Society, London, UK, June 25-26.

Durr, J. K., Herold-Schmidt, U., Zaglauer, H. W. and Arents, F. J., 1999. "On the Integration of Piezoceramic Actuators in Composite Structures for Aerospace Applications," Journal of Intelligent Material Systems and Structures, Vol. 10, No. 11, pp. 880-889, November.

Duvernier, M., Reithler, L., Guerrero, J. Y. and Rossi, R., 2000. "Active Control System for a Rotor Blade Trailing Edge Flap," in Smart Swuctures and Materials 2000: Smart Structures and Integrated Systems, N. W. Wereley (Ed.), SPIE Vol. 3985, pp. 52-61, 2000.

Fink, D. A., Hawkey, T. J. and Gaudreau, P. J., 2000. "An Electromagnetic Actuator for Individual Blade Control," 56th Annual Forum of the American Helicopter Society, Virginia Beach, VA, May 2-4.

Fulton, M. and Ormiston, R. A., 1997. "Hover Testing of a Small-Scale Rotor with On-Blade Elevons," Proceedings of the 53rd Forum of the American Helicopter Society, Virginia Beach, VA, April 29-May 1.

Fulton, M. and Ormiston, R. A., 1998. "Small-Scale Rotor Experiments with On-Blade Elevons to Reduce Blade Vibratory Loads in Forward Flight," Proceedings of the 54th Forum of the American Helicopter Society, Washington DC, 1998.

Giurgiutiu, V., Chaudhry, Z. and Rogers, C. A., 1994. "Engineering Feasibility of Induced-Strain Actuators for Rotor Blade Active Vibration Control," Smart Structures and Materials '94, Orlando, Florida, 13-18 February, Paper \# 2190-11, SPIE Volume 2190, pp. 107-122.

Giurgiutiu. V., Chaudhry, Z. and Rogers, C. A., 1997a. "Design of Displacement Amplified Induced Strain Actuators for Maximum Energy Output," ASME Journal of Mechanical Design, Vol. 119, No. 4, December, pp. $421-524$.

Giurgintiu, V., Craig, A. and Rogers, C. A., 1997b. "Power and Energy Characteristics of Solid-State Induced-Strain Actuators for Static and Dynamic Applications," Journal of Intelligent Material Systems and Structures, Vol. 8, September.

Hall, S. R. and Prechl, E. F., 1996. "Development of a Piezoelectric Servoflap for Helicopter Rotor Control," Journal of Smart Materials and Structures, Vol. 5, pp. 26-34, February.

Hall, S. R. and Prechl, E. F., 1999. "Preliminary Testing of a Mach-Scaled Active Rotor Blade with a Trailing Edge Servo-Flap," SPIE Smart Structures and Materials Symposium, Newport Beach, CA, 1-5 March, paper \# 3668-03.

Hall, S. R., Tzianetopolou, T., Straub, F. and Ngo, H., 2000. "Design and Testing of a Double X-Frame Piezoelectric Actuator," in Smart Structures and Materials 2000: Smart Structures and Integrated Systems, N. W. Wereley (Ed.), SPIE Vol. 3985, pp. 26-37, 2000. 
Heeg, J., 1993. “Analytical and Experimental Investigation of Flutter Suppression by Piezoelectric Actuation," NASA Technical Paper 3241.

Hopkins, M., Henderson; D., Moses, R., Ryall, T., Zimcik, D. and Spangler, R., 1998. "Active Vibration Suppression Systems Applied to Twin Tail Buffeting," SPIE Vol. 3326, pp. 27-33.

Koratkar, N. A. and Chopra, I., 1998. "Analysis and Testing of a Mach Scaled Helicopter Rotor in Hover with Piezoelectric Bender Actuated Trailing-Edge Flaps," SPIE's 1998 Symposium on Smart Structures and Materials, San Diego, CA, March, SPIE Vol. 3329, pp. 321-332.

Koratkar, N. A. and Chopra, I., 2000. "Hover Testing of a Mach-Scaled Rotor with Piezoelectric Bender Actuated Trailing Edge Flaps," in Smart Structures and Materials 2000: Smart Structures and Integrated Systems, N. W. Wereley (Ed.), SPIE Vol. 3985, pp. 2-10.

Kennedy, D. K., Straub, F. K., Schetky, L. McD., Chaudhry, Z. and Roznoy, R., 2000. "Development of a SMA Actuator for In-Fiight Rotor Blade Tracking," in Smart Structures and Materials 2000: Smart Swactures and Integrated Systems, N. W. Wereley (Ed.), SPIE Vol. 3985, pp. 62-75.

Lee, T. and Chopra, I., 1998. "Design and Static Testing of a Trailing-Edge Flap Actuator with Piezostacks for a Rotor Blade," SPIE Vol. 3329, pp. 321-332.

Lee, T. and Chopra, I., 2000. "Development of a Smart Trailing-Edge Flap Actuator with Multi-Stage Stroke Amplifier for a Rotor Blade," in Smart Structures and Materials 2000: Smart Structures and Integrated Systems, N. W. Wereley (Ed.), SPIE Vol. 3985, pp. 11-25.

Larson, C. R., Falanges, E. and Dobbs, S. K., 1998. "Piezoceramic Active Vibration Suppression Control System Development for the B-IB Aircraft," SPIE 5th Smart Structures and Materials Symposium, San Diego, CA.

Manser, R., Simpson, J., Becker, J., Durr, J., Floth, E., Herold-Schmidt, U., Stark, H. and Zaglauer, H. W., 1999. "Fin-Buffet Alleviation via Distributed Piezoelectric Actuators. Full Scale Demonstrator Tests," SPIE 6th Smart Structures and Materials Symposium, Newport Beach, CA, March.

McGowan, A-M. R., Wilkie, W. K., Moses, R. W., Lake, R. C., Florance, J. P., Wieseman, C. D., Reaves, M. C., Taleghani, B. K., Mirick, P. H. and Wilbur, M. L., 1998. "Aeroservoelastic and Structural Dynamics Research on Smart Structures Conducted at NASA Langley Research Center," SPIE Vol. 3326, pp. 188-201.

Millott, T. A. and Friedmann, P. P., 1994. "Vibration Reduction in Hingeless Rotors in Forward Flight Using an Actively Controlled Trailing Edge Flap: Implementation and Time Domain Simulation," Proceedings of the AIAA/ASME/ASCE/AHS/ASC 35th Structures, Structural Dynamics, and Materials Conference, Hilton Head, SC, April 18-20, paper AIAA-94-1306-CP, pp. 8-22.

Morris, D. G., Pizzochero, A. and Hagood, N. W., 1999. "Experimental Investigation of the Effect of Environmental Stress on Active Fiber Composite Actuators," SPIE Vol. 3674 (in press).

Moses, R. W., 1997a. "Vertical Tail Buffeting Alleviation Using Piezoelectric Actuators-Some Results of the Actively Controlled Response of Buffet-Affected Tails (ACROBAT) Program," SPlE's 4th Annual Symposium on Smart Structures and Materials, Industrial and Commercial Applications of Smart Structures Technologies, SPIE Vol. 3044, San Diego, California, March 4-6, pp. 87-98.

Moses, R. W., 1997b. "Active Vertical Tail Buffeting Alleviation on a Twin-Tail Fighter Configuration in a Wind Tunnel," CEAS International Forum on Aeroelasticity and Structural Dynamics 1997, Rome, Italy, June $17-20$.

Moses, R. W., 1999. "Contributions to Active Buffeting Alleviation Programs by the NASA Langley Research Center," 40th AIAA/ASME/ASCE/AHS/ASC Structures, Structural Dynamics, and Materials Conference, St. Louis, Missouri, paper \#AlAA99-1318, April $12-15$.

Narkiewicz, J. P. and Done, G. T. S., 1994. "Overview of Smart Structure Concepts for Helicopter Rotor Control," 2nd European Conference on Smart Structures and Materials, Glasgow, U.K.

Nitzsche, F. and Breitbach, E., 1992. "Study of Feasibility of Using Adaptive Structures in the Attenuation of Vibration Characteristics of Rotary Wings," AIAA paper no. AIAA-92-2452-CP.

Nitzsche, F., 1993. "Modal Sensors and Actuators for Individual Blade
Control," Proceedings of the AIAA/ASME/ASCE/AHS/ASC 34th Structures, Structural Dynamics, and Materials Conference, La Jolla, CA, April, paper AIAA-93-1703-CP, pp. 3507-3516.

Prechl, E. F. and Hall, S. R., 1997. "Design of a High Efficiency Discrete Servo-Flap Actuator for Helicopter Rotor Control," SPIE Vol. 3041, pp. 158-182.

Prechtl, E. F. and Hall, S. R., 1998. "An X-frame Actuator Servo-Flap Actuation System for Rotor Control," SPIE Vol. 3329, pp. 309-319.

Rodgers, J. P. and Hagood, N. W., 1998. "Preliminary Mach-Scale Hover Testing of an Integrated Twist-Actuated Rotor Blade," SPIE Vol. 3329, pp. 291-308.

Simpson, J. and Schweiger, J., 1998. "Industrial Approach to Piezo-Electric Damping of Large Fighter Aircraft Components," SPIE 5th Smart Structures and Materials Symposium, San Diego, CA.

Schweiger, J., Simpson, J., Weiss, F., Coetzee, E. and Boller, C., 1999. "Needs for the Analysis and Integrated Design Optimization of Active and Passive Structures for Active Aeroelastic Wings," SPIE 6th Smart Structures and Materials Symposium, Newport Beach, CA, March.

Spangler, R. L. Jr. and Hall, S. R., 1989. "Piezoelectric Actuators for Helicopter Rotor Control," Report \# SSL 1-89, SERC 14-90, MIT Space Engineering Research Center, Massachusetts Institute of Technology, Cambridge, Massachusetts 02139, Jan.

Spencer, M. G., Sanner, R. M. and Chopra, R. I., 1999. “Adaptive Neurocontrol of Simulated Rotor Vibrations Using Trailing Edge Flaps," Journal of Intelligent Material Systems and Structures, Vol. 10, No. 11, pp. 855-871, November.

Spencer, M. G., Sanner, R. M. and Chopra, R. I., 2000. "Closed-loop Hover Test Results with a Neurocontroller on Piezoactuated Smart Rotor Blades," in Smart Structures and Materials 2000: Smart Structures and Integrated Systems, N. W. Wereley (Ed.), SPIE Vol. 3985, pp. 38-49.

Straub, F. K., 1993. "A Feasibility Study of Using Smart Materials for Rotor Control," 49th Annual Forum of the American Helicopter Society, St. Louis, MO, May 19-21.

Straub, F. K. and Merkley, D. J., 1995. "Design of a Smart Material Actuator for Rotor Control," SPIE Smart Structures and Materials Symposium, San Diego, CA, February 26-March 3.

Straub, F. K. and King, R. J., 1996. "Application of Smart Materials to Control of a Helicopter Rotor," SPIE Symposium on Smart Structures and Materials, San Diego, CA, February 26-29, 1996.

Straub, F. K., Ealey, M. A. and Schetky, M. L. M., 1997. "Application of Smart Materials to Helicopter Rotor Active Control," SPIE Vol. 3044, pp. 99-113, 1997.

Straub, F. K., 1999. "Development of a Full Scale Smart Rotor System," 8th ARO Workshop on Aeroelasticity of Rotorcraft Systems, Penn State University, October 18-20.

Walz, C. and Chopra, I., 1994. "Design, Fabrication, and Testing of a Helicopter Rotor Model with Smart Trailing Edge Flaps," Proceedings of the AIAA/ASME/ASCE/AHS/ASC 35th Structures, Structural Dynamics, and Materials Conference-Adaptive Structures Forum, Hilton Head, SC, April 21-22, paper AIAA-94-1767-CP, pp. 298-319.

Wilbur, M. L., Wilkie, W. K., Yeager, Jr., W. T., Lake, R. C., Langston, W., Cesnik, C. E. S. and Shin, S. J., 1999. "Hover Testing of a NASA APL/MIT Active Twist Rotor," 8th ARO Workshop on Aeroelasticity of Rotorcraft Systems, Penn State University, October 18-20.

Wilkie, W. K., Belvin, W. K. and Park, K. C., 1998. "Torsional Stiffness Optimization of Piezoelectric Active Twist Helicopter Rotor Blades," Proceedings of the 9th International Congress on Adaptive Structures and Technologies, October 14-16, Boston, MA, pp. 213-224.

Wilkie, W. K., Wilbur, M. L., Mirick, P. H., Cesnik, C. E. S. and Shin, S. J., 1999. "Aeroelastic Analysis of the NASA ARMY/MIT Active Twist Rotor," 55th Annual Forum of the American Helicopter Society, Montreal, Canada, May 25-27.

Wilkie, W. K., High, J. W., Mirick, P. H., Fox, R. L., Little, B. D., Bryant, R. G. and Hellbaum, R. F. J. A. Jr. (2000) "Low-cost Piezocomposite Actuator for Structural Control Applications," SPIE 7th Annual International Symposium on Smart Structures and Materials, 5-9 March, Newport Beach, CA, paper \# 3991-42. 